Estudios Constitucionales, Año 15, No 1, 2017, pp. 15 - 54

ISSN 07180195

Centro de Estudios Constitucionales de Chile Universidad de Talca

"Los usos del Derecho Internacional de los Derechos Humanos

en la jurisprudencia de los Tribunales Superiores de Justicia en Chile"

\title{
LOS USOS DEL DERECHO INTERNACIONAL DE LOS DERECHOS HUMANOS EN LA JURISPRUDENCIA DE LOS TRIBUNALES SUPERIORES DE JUSTICIA EN CHILE**
}

The application of International Human Rights LaW IN THE JURISPRUDENCE OF THE HIGHER COURTS OF JUSTICE IN CHILE

\author{
Claudio Nash** \\ Universidad de Chile, cnash@derecho.uchile.cl \\ CONSTANZA NúNEZZ*** \\ Universidad de Chile,cnunez@derecho.uchile.cl
}

RESUMEN: El articulo analiza las funciones y usos que la jurisprudencia de los tribunales superiores de Chile (Cortes de Apelaciones y Corte Suprema) dan al Derecho Internacional de los Derechos Humanos al momento de resolver casos contenciosos sometidos a su jurisdicción. Se plantea por los autores que pese a la falta de claridad en el diseño constitucional en torno a la jerarquía que ocupan los tratados internacionales sobre derechos humanos, esto no ha obstado para que los tribunales superiores de justicia hayan dado diferentes usos sustantivos al DIDH, que han permitido, en definitiva, dar coherencia al ordenamiento jurídico, mejorar la efectividad de la protección de los derechos fundamentales y cumplir con las obligaciones internacionales asumidas por el Estado.

ABSTRACT: The article analyzes the functions and uses that the jurisprudence of the superior courts of Chile (Courts of Appeals and Supreme Court) give to the International Human Rights Law in the moment to settle contentious cases under its jurisdiction. It is argued by the authors that, despite the lack of clarity in the constitutional design around the hierarchy of international human rights treaties, this has not prevented higher courts of justice from giving different substantive uses to the IHRL, which

\footnotetext{
* Trabajo recibido el 10 de marzo de 2017 y aprobado el 26 de abril de 2017.

** Doctor en Derecho, Universidad de Chile. Profesor asistente Facultad de Derecho, Universidad de Chile. Director de la Cátedra de Derechos Humanos de la misma Universidad.

*** Licenciada en Ciencias Jurídicas y Sociales de la Universidad de Chile. Académica instructora de la Facultad de Derecho Universidad de Chile. Actualmente cursando estudios de posgrado en el Instituto Bartolomé de las Casas de la Universidad Carlos III de Madrid.

Artículo desarrollado en el marco del proyecto de investigación Fondecyt No 1150571, titulado "Recepción jurisdiccional sustantiva de la normativa y jurisprudencia internacional en Chile. El proceso de reconfiguración de los derechos fundamentales y su impacto en la protección de grupos discriminados". Agradecemos la ayuda en esta investigación de Camila Troncoso y Camilo Cornejo. Agradecemos también las perspectivas brindadas por defensores/as penales públicos, jueces/zas y fiscales, en el contexto de talleres desarrollados en el curso de la investigación, que nos permitieron ampliar la visión sobre los diferentes usos del DIDH en la jurisprudencia.
} 
have made it possible to give coherence to the legal system, to improve the effectiveness of the protection of fundamental rights and to comply with the international obligations assumed by the State.

PALABRAS CLAVE: usos DIDH, funciones del DIH.

KEYWORDS: uses of IHRL, functions of IHRL.

\section{INTRODUCCIÓN}

El estudio que se presenta a continuación tiene por objetivo analizar las funciones y usos que la jurisprudencia de los tribunales superiores de justicia en Chile (Cortes de Apelaciones y Corte Suprema), dan al Derecho Internacional de los Derechos Humanos (en adelante, DIDH) al momento de resolver casos contenciosos sometidos a su jurisdicción.

Se buscará demostrar que pese a los obstáculos que presenta el diseño constitucional en torno a la jerarquía que ocupan los tratados internacionales sobre derechos humanos en el ámbito interno, esto no ha obstado para que los tribunales superiores de justicia, paulatinamente, hayan dado diferentes usos sustantivos al DIDH, que han permitido, en definitiva, dar coherencia al ordenamiento jurídico, mejorar la efectividad de la protección de los derechos fundamentales y cumplir con las obligaciones internacionales asumidas por el Estado. Asimismo, se ilustrará cómo se han ampliado los temas respecto de los cuales la jurisprudencia hace uso del DIDH ${ }^{1}$. Para ello, se ha decidido realizar un análisis de la jurisprudencia de las Cortes de Apelaciones y Corte Suprema en consideración a la competencia que tienen para conocer de acciones de tutela de derechos fundamentales (protección y amparo); asimismo, se ha analizado la jurisprudencia de estas Cortes en todos los ámbitos de su competencia: penal, familia, laboral y civil ${ }^{2}$.

Nos ha parecido relevante estudiar la recepción jurisprudencial del DIDH en tribunales ordinarios, considerando que tradicionalmente se ha asociado la labor de aplicación de la normativa constitucional como una función exclusiva del juez/a constitucional. Sin embargo, el deber de garantía de los derechos

1 Los temas tradicionales habían sido violaciones masivas y sistemáticas y prisión por deudas. Este es un tema que ha sido ampliamente destacado en la doctrina, véase, por ejemplo, IRIGOIN, (1996) y FERNÁNDEZ (2010). A modo de ejemplo de esta tendencia jurisprudencial inicial en las cortes nacionales, véase: Corte Suprema. Rol No 2054-2008, de 18 de junio de 2008.

2 El estudio comienza en el año 2005, año en que la Corte Suprema de Chile abandonó la competencia de conocimiento de la acción de inaplicabilidad por inconstitucionalidad, recayendo su conocimiento en el Tribunal Constitucional. 
humanos es un mandato para toda la autoridad pública ${ }^{3}$, es por ello que resulta interesante conocer de qué manera los tribunales ordinarios se hacen cargo -en su argumentación- de esta obligación, y de qué manera justifican la aplicación de estándares internacionales. Asimismo, se ha escogido esta jurisdicción en consideración a la poca atención que ha concitado en la doctrina el estudio de esta sede jurisdiccional ${ }^{4}$, a diferencia de la práctica del Tribunal Constitucional5.

Este estudio, en primer lugar, se referirá a aspectos generales del escenario actual sobre interacción entre el DIDH y el derecho interno, poniendo especial énfasis en la manera que se ha tratado este proceso en Chile desde la perspectiva académica. En segundo lugar, se ilustrará la función de legitimación del DIDH y los usos que se le ha dado por parte de la jurisprudencia nacional. Luego, se realizarán algunas observaciones acerca de la justificación teórica y práctica de la utilización del DIDH. Finalmente, se harán algunas conclusiones generales.

\section{ConteXto: La Relación ENTRE DEL DIDH y El DERECHO INTERNO}

Uno de los fenómenos más relevantes de los últimos 30 años en materia de derechos humanos ha sido la convergencia de dos sistemas normativos que consagran normas y mecanismos de garantía para el pleno goce y ejercicio de los derechos: el DIDH y los sistemas nacionales de jurisdicción constitucional6. Dicho proceso de convergencia se basa en una efectiva coordinación entre los mecanismos de protección asociados a cada sistema normativo, de forma tal que cada uno aporte en la consecución de un objetivo común: la efectiva protección de los derechos humanos ${ }^{7}$. En ese sentido, ha surgido la pregunta acerca de cuál es la naturaleza de este proceso de interacción entre ambos sistemas.

Tradicionalmente se ha entendido al sistema internacional como subsidiario del nacional ${ }^{8}$ y, consecuencialmente, el DIDH debería aplicarse sólo cuando el sistema interno no ha dado respuesta ante determinadas violaciones de derechos

3 Artículos 1.1 y 2 de la Convención Americana sobre Derechos Humanos (CADH).

4 Con las excepciones de los estudios de Irigoin (1996); Aguilar (2009); Fernández (2010), y HenríqueZ, (2010).

5 Véase, entre otros, los estudios de Peña (2008); Núñez Poblete (2009); Nogueira (2012), y VieraGallo y LÜBBert (2012).

6 RIsSo (2012).

7 LANDA (2012).

8 Benadava (1992). 
fundamentales ${ }^{9}$. Sin embargo, actualmente no resulta factible aplicar esta visión a la totalidad de las materias a las cuales está sujeta esta relación entre sistemas, como, por ejemplo, a la labor de codificación y promoción que realiza el DIDH ${ }^{10}$. De ahí que se haya planteado por la doctrina que la relación existente entre los sistemas constitucional e internacional debe ser entendida como una de carácter complementaria ${ }^{11}$. De acuerdo con esta concepción, las normas de fondo de derechos humanos (como las consagradas en los tratados internacionales) pasan a integrar, precisar y enriquecer el contenido de los derechos reconocidos en la Constitución. Esta perspectiva considera que las normas del ordenamiento interno y del internacional tienen un sentido y alcance que deben articularse en un sistema en donde ninguna anule a la otra, ni estén en pugna, sino que deben aplicarse de tal modo que se alcance una congruencia armonizante, al ser ambas fuentes del derecho interno ${ }^{12}$.

Esta correlación entre los ordenamientos normativos, nacional e internacional, ha sido destacada por la doctrina como un proceso de "internacionalización" del derecho constitucional y de "constitucionalización" del DIDH13. El resultado de ambos procesos (internacionalización y constitucionalización) ha traído consigo que los derechos humanos tengan una doble fuente normativa: nacional e internacional, y ello hace que los mismos tengan una doble fuente judicial en los tribunales encargados de interpretarlos ${ }^{14}$. De esta forma, a través de esta interpretación de doble fuente normativa los sistemas interactúan retroalimentándose. Este proceso es lo que García Sayán -ex presidente de la Corte IDH- ha llamado "viva interacción" entre los tribunales internacionales

9 Por ello, serían los Estados como los primeros llamados a cumplir con la labor de protección de los derechos humanos, véase: CANÇADO (2001) y NASH (2010). Normativamente esto se expresa en el principio de agotamiento previo de los recursos internos, que en el ámbito interamericano se encuentra contemplado en el artículo 46.1 de la Convención Americana sobre Derechos Humanos.

10 NASH (2013).

11 CANÇADO (2001).

12 NASH (2013).

13 Ferrer Mac-Gregor (2012). La internacionalización del derecho constitucional de los derechos humanos correspondería a aquel proceso que se inicia, progresivamente, tras la Segunda Guerra Mundial y mediante el cual se crean catálogos de derechos humanos y organismos de protección internacional que buscan fortalecer y colaborar con las jurisdicciones nacionales en su labor de promoción y protección de los derechos fundamentales. La constitucionalización del DIDH, por su parte, se relaciona con la progresiva aplicabilidad del DIDH en el ámbito interno, a través de diversas fórmulas y cláusulas constitucionales.

14 AyAla (2013). 
y los tribunales internos ${ }^{15}$ o es el llamado "diálogo jurisprudencial" a que alude la doctrina latinoamericana y europea ${ }^{16}$.

Pese a los distintos diseños institucionales de recepción del DIDH en el ámbito interno en la región, una de las principales manifestaciones de la interacción entre el DIDH y el derecho interno se da en la jurisprudencia de los tribunales con competencia constitucional, donde se ha pasado desde una recepción formal a una sustantiva de la normativa y estándares internacionales en sede interna ${ }^{17}$, proceso que finalmente ha reconfigurado la concepción de derechos fundamentales en la región ${ }^{18}$. El uso de la figura del bloque de constitucionalidad y la interpretación pro persona han sido determinantes para dicha convergencia argumentativa ${ }^{19}$.

\section{La RECEPCión Formal y SUSTANCIAL DEL DIDH EN Chile}

En general, la recepción de los tratados de derechos humanos no tiene problemas diferentes de los de la recepción del resto de los tratados ${ }^{20}$. Sin embargo,

15 García Sayán (2005).

16 Ferrer Mac-Gregor (2012), Ayala (2013) y Martín, et al., (2013). Este fenómeno ha sido reconocido por la propia Corte IDH, que en su informe del año 2010, indicó “Durante 2010 el 'diálogo jurisprudencial' entre la Corte Interamericana, órganos judiciales superiores a nivel interno. Este diálogo ha tenido dos efectos concretos y palpables en los últimos años. Por un lado, a nivel interno se puede verificar un creciente número de países que incorporan los estándares interamericanos de derechos humanos fijados por la Corte. Por el otro, la Corte se ve enormemente beneficiada de la jurisprudencia producida a nivel local, lo que ayuda además al desarrollo de su propia jurisprudencia. Esto genera una dinámica que enriquece la jurisprudencia del Tribunal y fortalece la vigencia de los derechos humanos en todos los Estados del hemisferio, ya que la protección internacional de los derechos humanos encuentra aplicación directa en el ámbito interno por parte de los tribunales locales o de cualquier órgano estatal encargado de impartir justicia" (Corte IDH. Síntesis del informe anual de la Corte IDH correspondiente al ejercicio 2010 que se presenta a la comisión de asuntos jurídicos y políticos de la OEA, 18 de marzo de 2011, párr. 4).

17 La incorporación formal se refiere al proceso mediante el cual la norma de DIDH pasa a tener valor en el ordenamiento jurídico interno, esto es, pasa a ser norma integrante del corpus iuris del Estado. Por su parte, la incorporación sustantiva se basa en la adopción de estándares sustantivos desarrollados por el sistema internacional de derechos humanos, para resolver cuestiones institucionales, normativas y jurisdiccionales al interior de los Estados, véase: NASH y NúNEZ (2017).

18 NASH (2010). Claros ejemplos de esta recepción encontramos en los razonamientos de los tribunales constitucionales y tribunales ordinarios en temas como obligaciones positivas de los Estados, restricciones y juicio de ponderación, bloque de constitucionalidad, estado de cosas inconstitucional, entre otras. Cada una marcada por las tendencias internacionales en materia constitucional y por los avances en la jurisprudencia internacional

19 NaSH y NúÑ̃ez (2017).

20 García Barzelato (2006) y Nogueira (2007). 
cuando nos enfrentamos ante la problemática de la jerarquía, existen diferencias de tratamiento en el ordenamiento jurídico chileno ante tratados de derechos humanos $^{21}$. De esta forma, la discusión ha quedado centrada en la recepción formal, a fin de determinar el rango de los derechos humanos consagrados en tratados internacionales (supralegal, constitucional o supraconstitucional) ${ }^{22}$.

Los términos en que está redactado el artículo $5^{\circ}$ inciso $2^{\circ}$ de la Constitución $^{23}$ han permitido interpretaciones contrapuestas respecto al rango que ocupan los derechos humanos en la pirámide normativa. Este problema del diseño institucional, sin duda, ha ralentizado el proceso de recepción jurisdiccional del DIDH en el ámbito interno, pero no lo ha impedido por completo ${ }^{24}$. En efecto, desde 2004 en adelante se ha ido desarrollando un proceso creciente de recepción sustantiva del DIDH por parte de la jurisprudencia de las Cortes de Apelaciones y Corte Suprema que ha permitido una mejor protección de los derechos humanos, esto es, resolviendo de una manera adecuada cuestiones que se venían resolviendo restrictivamente y dando respuesta a cuestiones hasta ahora no resueltas.

Por ello, es importante preguntarse ¿cuál es la función que cumple el DIDH como elemento de legitimación de la actividad estatal?, ¿cuál es el uso que se le ha dado al DDIH por parte de la jurisprudencia constitucional al momento de resolver cuestiones contenciosas en el ámbito interno? y ¿qué justifica la utilización del DIDH como parte del proceso argumentativo de la judicatura constitucional?

21 Un completo estudio de la evolución jurisprudencial en este tema en Henríquez (2008). La Corte Suprema se ha inclinado por la tesis de la constitucionalización, véase, por ejemplo: Corte Suprema. Rol No 517-2004, de 17 de noviembre de 2004; Rol No 559-2004, de 13 de diciembre de 2006; Rol No 31252004, de 13 de marzo de 2007; Rol No 2054-2008, de 18 de junio de 2008; rol No 3452-2006, de 10 de mayo de 2007; Rol No 1528-2006, de 24 de enero de 2008 y; Rol No 3841-2012, de 4 de septiembre de 2013. El Tribunal Constitucional se ha inclinado por la tesis del rango simplemente legal, ver causa rol No 346-2002, de 8 de mayo de 2002. Este punto de vista se reafirma en la sentencia Rol No 1288-2009, de 9 de agosto de 2009, donde el Tribunal Constitucional somete a los tratados internacionales a un control represivo de constitucionalidad y en la sentencia sobre constitucionalidad de la Ley de Pesca, roles $\mathrm{No}_{\text {s. }} 2387$ y 2388 acumulados.

22 El debate se puede apreciar en los estudios de Fernández (1989); Nogueira (1996); Pfeffer (2003); Aldunate (2010), entre otros.

23 Artículo 5.2 Constitución Política: "El ejercicio de la soberanía reconoce como limitación el respeto a los derechos esenciales que emanan de la naturaleza humana. Es deber de los órganos del Estado respetar y promover tales derechos, garantizados por esta Constitución, así como por los tratados internacionales ratificados por Chile y que se encuentren vigentes".

24 NASH y NúNEZ (2017). 
A continuación, se desarrollará la función que se le reconoce al DIDH y algunos de los usos que se le han dado en la jurisprudencia chilena, desde una perspectiva sustantiva ${ }^{25}$.

\section{Función del DiDH para legitimar la ACTIVIDAD DEl EsTAdo}

La aplicación de los estándares internacionales en el ámbito interno no sólo es un elemento que "limita" la actividad del Estado, sino que, básicamente, es un parámetro de legitimidad de dicha actividad ${ }^{26}$. Esto cobra especial relevancia en casos donde la legislación otorga amplios espacios de actuación a los agentes estatales. Esta postura ha sido ampliamente recogida por la jurisprudencia nacional. Incluso en casos donde la ley entrega un espacio de discrecionalidad, tanto el Tribunal Constitucional ${ }^{27}$ como la Corte Suprema han establecido un parámetro único: la discrecionalidad en ningún caso significa descontrol y, menos, arbitrariedad. Para definir cuál es la base de dicho control y cuál es el límite de la discrecionalidad para que no constituya arbitrariedad, los derechos humanos tienen un papel fundamental, en particular, aquellos que provienen de fuentes internacionales.

Por ejemplo, la Corte Suprema, en un caso relativo a migración, donde la discrecionalidad entregada a la autoridad administrativa es evidente, señaló:

"Que la potestad discrecional es una herramienta de la autoridad administrativa que se caracteriza por otorgar un margen de libertad para decidir de una manera u otra,

25 En el ámbito normativo e institucional es claro que la recepción sustancial ha influenciado procesos de reforma constitucional (véanse, por ejemplo, artículo 19 No 12 de la Constitución Política) y legal (reforma procesal penal, reforma a la justicia penal adolescente), pero en el ámbito jurisprudencial, la respuesta ha sido menos amplia y profunda. A diferencia de la experiencia comparada en Latinoamérica (Perú, Colombia, México, Argentina), véase, por ejemplo: Abregú y Courtis (1997), en Chile la doctrina no ha profundizado en el estudio de la recepción de estándares sustantivos por parte de la jurisprudencia. Gran parte de los estudios existentes en la materia, centran su atención principalmente en el análisis de la aplicación de estándares internacionales para resolver casos relacionados con violaciones masivas y sistemáticas a los derechos humanos perpetradas en la dictadura militar. A modo de ejemplo véase, AgUilar (2009) y AgUiLAR (2013).

26 Como destaca Ferrajoli, una de las características del constitucionalismo en relación a los derechos, reside en haber incorporado como normas de legitimación interna, gran parte de las fuentes de justificación externa "relativas al 'cuándo' y al 'cómo' del ejercicio de los poderes públicos" (Ferrajoli (1995), p. 213). En este caso, los criterios de legitimación respecto al 'cómo' ejercer el poder público también estarían en fuentes del DIDH.

27 Tribunal Constitucional. Rol No 198-1995, 4 de enero de 1995, considerando 10; Rol No 2026-2011, 14 de agosto de 2012 , considerando $15^{\circ}$. 
sin que su actuar se encuentre determinado previamente por una regla contenido en una norma jurídica. No obstante ello, la discrecionalidad jamás puede invocarse para encubrir una arbitrariedad que prive, perturbe o amenace los derechos fundamentales de alguna persona.

$(\ldots)$

"Del mismo modo, el Derecho Internacional Humanitario ha fijado ciertos parámetros sobre los cuales los Estados parte deben ejercer la potestad de denegar el ingreso al país de un extranjero. Así, aunque en principio el Pacto Internacional de Derechos Civiles y Políticos"28 (subrayado nuestro).

Y respecto del rol de la judicatura, como base del control, la Corte de Apelaciones de Santiago ha señalado:

"Que los actos de la administración deben estar siempre supeditados al imperio del Derecho, correspondiendo a los Tribunales de Justicia velar por su acatamiento. (...)

"Que, desde esa perspectiva y teniendo en cuenta la doble antijuridicidad que exige la protección de la garantía invocada, lo que corresponde a esta Corte elucidar es si la autoridad recurrida se sujetó en su actuación al derecho y si a dicha actuación es dable atribuirle notas de la arbitrariedad que proscribe nuestro ordenamiento. (...)"29 (subrayado nuestro).

En cuanto a la concesión de visados, el DIDH opera como criterio interpretativo para delimitar las facultades discrecionales de la autoridad pública. En este sentido, el DIDH aporta criterios no sólo para sostener una interpretación restrictiva de los límites al derecho de libertad de circulación y residencia, sino que entrega los parámetros que legitiman dicha regulación:

"[...] la potestad discrecional es una herramienta de la autoridad administrativa que se caracteriza por otorgar un margen de libertad para decidir de una manera u otra, sin que su actuar se encuentre determinado previamente por una regla contenido en una norma jurídica. No obstante ello, la discrecionalidad jamás puede invocarse para encubrir una arbitrariedad que prive, perturbe o amenace los derechos fundamentales de alguna persona. Pues, por aplicación del artículo $6^{\circ}$ de la Constitución Política de la República, la autoridad -aun en el ejercicio de su competencia- está obligada a res-

28 Corte Suprema. Rol No 11521-2014, 12 de junio de 2014, considerando 5º.

29 Corte de Apelaciones de Santiago. Rol No 8413-2013, 1 de agosto de 2013, considerandos $8^{\circ}$ y 9 o respectivamente. 
petar todas las normas del texto constitucional, entre las que evidentemente se incluye el derecho a la libertad personal y la seguridad individual del artículo 19 № 7 [...].

"En este sentido, el Derecho Internacional Humanitario ha fijado ciertos parámetros sobre los cuales los Estados parte deben ejercer la potestad de denegar el ingreso al país de un extranjero. Así, aunque en principio el Pacto Internacional de Derechos Civiles y Políticos no reconoce a los extranjeros el derecho a entrar en el territorio de un Estado Parte ni de residir en él, correspondiendo a cada Estado Parte decidir a quién ha de admitir en su territorio, la Observación General No 27 sobre la situación de los extranjeros con arreglo al Pacto Internacional de Derechos Civiles y Políticos, aprobada en el $67^{\circ}$ período de sesiones del Comité de Derechos Humanos de las Naciones Unidas en 1999, indica en sus párrafos 13 y 14 que las reglas que limitan el derecho de ingreso de un extranjero a un país 'no debe(n) comprometer la esencia del derecho (...) no se debe invertir la relación entre derecho y restricción, entre norma y excepción. (...) Que las restricciones se utilicen para conseguir fines permisibles; deben ser necesarias también para protegerlos. Las medidas restrictivas deben ajustarse al principio de proporcionalidad; deben ser adecuadas para desempeñar su función protectora; debe ser el instrumento menos perturbador de los que permitan conseguir el resultado deseado, y deben guardar proporción con el interés que debe protegerse"”30.

De esta forma, el DIDH pasa a cumplir una función de legitimación de la actividad estatal. Deja de ser un mero límite y se transforma en un criterio de validez sustantiva ${ }^{31}$.

\section{USOS DEL DIDH EN LA JURISPRUDENCIA CHILENA}

Para poder analizar los usos que se le da al DIDH por la jurisprudencia nacional, se debe entender el DIDH de manera amplia, es decir, el conjunto de tratados, declaraciones y la práctica normativa de los tratados que surge de su aplicación por parte de los órganos internacionales de derechos humanos ${ }^{32}$. Asimismo, se analizarán sentencias nacionales que realizan un uso sustantivo del DIDH, es decir, aquellas en que la utilización del DIDH sea determinante para la resolución del

30 Corte Suprema. Rol No 1059-2015, 20 de enero de 2015, considerandos 4 y 5. En el mismo sentido: Corte Suprema. Rol No 11521-2014, 12 de junio de 2014 y Corte de Apelaciones de Iquique. Rol No 56-2015, 31 de marzo de 2015.

31 Sobre los derechos como criterios de validez sustantiva, véase: ANSUÁtegui (1997), pp. 65-86.

32 Respecto a la jurisprudencia, esta última es asumida con valor de lo que la doctrina llama "cosa interpretada" cuando el Estado no ha sido condenado por la jurisprudencia en cuestión. Sobre la diferencia entre res judicata y res interpretata, véase: FERRER-MAC GREGOR (2014). 
caso (que influyan en la ratio decidendi) ${ }^{33}$ y no aquellas resoluciones en que la mención al DIDH es descriptiva o enunciativa ${ }^{34}$. De esta forma, el énfasis estará puesto en las "sentencias de principio", esto es, en aquellas que "interpretan el alcance y sentido de las normas constitucionales, colman los vacíos normativos y forjan verdaderos precedentes vinculantes" 35 .

La categorización de los usos propuestas se ha realizado tomando en consideración estudios similares realizados a nivel de derecho comparado ${ }^{36}$, adaptando las categorías a los hallazgos jurisprudenciales en Chile ${ }^{37}$.

33 Saiz, en su estudio sobre la apertura constitucional al DIDH en el modelo español, distingue los usos de los tratados y la jurisprudencia internacionales como "ejemplo" y como "modelo". Como ejemplo, "la fuente de origen internacional contribuye a la justificación de una decisión ya adoptada". Como modelo, se trataría de aquel uso en que el DIDH "funda la decisión, es decir, cuando deviene instrumento principal -si no único- del razonamiento del intérprete”. SAIz (1999), p. 241. Es en este sentido último en que se trabajará sobre los usos del DIDH por los tribunales superiores de justicia en Chile.

34 Se trataría de aquellas sentencias que enumeran los tratados que regulan un derecho, y que al ser citados tienen sólo como fin reforzar un argumento que previamente ya había sido desarrollado (argumento de autoridad) o que operan bajo el argumento ad abundatiam. Como señala Queralt Jiménez en su estudio de la apertura del Tribunal Constitucional Español a las sentencias del Tribunal de Estrasburgo, "la aparente forma con la que venga presentada la referencia al o a los instrumentos interpretativos europeos, no determina, tampoco, el uso que de ellos vaya a hacerse; en otras palabras, lo aparentemente intenso o abundante de una cita no condiciona la incidencia real de la utilización del canon europeo como instrumento interpretativo en la jurisprudencia del TC”, en Queralt (2008), p. 218.

35 Landa distingue entre sentencias de especie y sentencia de principio, según la intensidad de la labor interpretativa por parte del órgano jurisdiccional. LANDA (2006), p. 8.

36 Véase, por ejemplo: Queralt (2008) (quien utiliza las categorías: test de conformidad, sentencias del TEDH como precedente en asuntos de complejidad fáctica, doble test de validez, guía interpretativa, muestras del desarrollo del ius commune europeo en materia de derechos fundamentales, incorporación de contenidos, entre otras.); Rey MarTínez (1989) (quien se refiere más bien específicamente a los usos de la cláusula de apertura del artículo 10.2 de la Constitución española, indicando que este artículo ha permitido jurisprudencialmente: indicar conexiones entre unos derechos y otros, reforzar argumentos, dotar de criterios objetivos a conceptos constitucionales indeterminados, delimitar el ámbito de titularidad de derechos fundamentales; precisar el sentido concreto y alcance de los derechos fundamentales; reintegrar derechos e introducir límites a los derechos fundamentales provenientes de los textos internacionales), y PÉrEz-TREMPS (2016) (que señala que los usos pueden concretarse en cinco: construcción del contenido, determinación de contenidos conexos o accesorios, determinación del contenido básico a efectos del control externo, rectificaciones de doctrina y canon de trascendencia constitucional).

37 Las sentencias escogidas representan de manera clara cada "uso", sin perjuicio de que en una misma sentencia puedan concurrir uno o más usos, o que existan otras sentencias en que el uso no sea claramente explícito. Si bien el uso más extendido del DIDH se da en materia de violaciones masivas y sistemáticas a los derechos humanos producidas en la dictadura militar, se han escogido sentencias de todas las materias investigadas (civil, penal, familia, laboral y recursos/acciones constitucionales), con el objeto de evidenciar un uso transversal del DIDH. 


\subsection{Concreción de principios}

La existencia de principios o conceptos jurídicos indeterminados en las leyes y constituciones es una constante en los ordenamientos jurídicos ${ }^{38}$. Estos principios y conceptos en casos vinculados con derechos fundamentales juegan un rol fundamental en la resolución de conflictos y también operan como parámetros interpretativos. En este sentido, la jurisprudencia chilena ha recurrido al DIDH para concretar estos principios y así puedan ser aplicados en casos concretos.

Un ejemplo clásico de este fenómeno, que no sólo se ha dado en Chile, sino también a nivel comparado ${ }^{39}$, es concretar el principio del "debido proceso" o "due process" ${ }^{2}$. En Chile el debido proceso se ha considerado que está consagrado de manera genérica en el artículo 19 No 3 de la Constitución Política (principio de un "procedimiento racional y justo"), de manera tal que la jurisprudencia nacional ha concretado este principio especificando las garantías que lo componen a la luz del $\mathrm{DIDH}^{41}$. Así ocurre también con el principio del interés superior del niño ${ }^{42}$ y la presunción de inocencia.

En cuanto al principio del interés superior del niño se ha reconocido su origen convencional, dotándolo de un triple contenido específico a la luz de las observaciones de los órganos de tratados:

38 Como destaca Guastini, "gran parte de las disposiciones constitucionales sustantivas utilizadas por los jueces constitucionales en las decisiones sobre la legitimidad constitucional de las leyes, no expresan reglas precisas, sino principios generales, los cuales exigen: por un lado, un proceso de concretización, para ser aplicados a controversias concretas". GUASTINI (2008), p. 73.

39 Véase al respecto el análisis que realiza Pérez-Tremps en relación a la incorporación en la jurisprudencia del Tribunal Constitucional del estándar del Tribunal Europeo de Derechos Humanos en materia de debido proceso, Pérez-Tremps (2016), p. 174.

40 Un caso ejemplar en esta materia en el derecho comparado, se puede encontrar en la sentencia No 1739-1992 de la Sala Constitucional de la Corte Suprema de Costa Rica.

41 Como son el derecho a defensa, el derecho al recurso, la contradicción y el plazo razonable. Véase, Corte Suprema. Rol No 7351-2009, 5 de enero de 2010; Corte Suprema. Rol No 2787-2010, 29 de mayo de 2010; Corte Suprema. Rol No 4001-2010, 24 de agosto de 2010; Corte de Apelaciones de San Miguel. Rol No 1537-2013, 18 de noviembre de 2013; Corte de Apelaciones de Concepción. Rol No 26-2014, 21 de marzo de 2014, y Corte de Apelaciones de Temuco. Rol No 253-2014, 24 de mayo de 2014.

42 Corte de Apelaciones de Santiago. Rol No 3427-2009, 16 de junio de 2010; Corte de Apelaciones de Santiago. Rol No 3383-2009, 8 de junio de 2010; Corte Suprema. Rol No 2556-2010, 16 de septiembre de 2010; Corte Suprema. Rol No 7220-2011, 30 de diciembre de 2011; Corte de Apelaciones de Santiago. Rol No 808-2012, 12 de abril de 2012; Corte Suprema. Rol No 920-2013, 7 de mayo de 2013, y Corte Suprema. Rol No 2843-2014, 8 de abril de 2014, entre otras. 
“(...) a saber: como derecho, como principio y como norma procesal (así lo plantea la Observación General No 14 del Comité de los Derechos del Niño de la Naciones Unidas), esto significa que se le reconocen tres dimensiones prioritarias: una consideración sustantiva; un principio jurídico interpretativo fundamental, y una fórmula procesal que obliga a estimar las posibles repercusiones de cada decisión, antes de ser adoptada”43.

En cuanto al principio de presunción de inocencia, siguiendo a la doctrina constitucional, se ha reconocido su concreción -por aplicación del DIDH-como un derecho fundamental:

"[...] la presunción de inocencia, desde la incorporación de la Convención Americana de Derechos Humanos al derecho interno, forma parte del bloque constitucional de derechos, dejando de ser un principio general del derecho que informa la actividad judicial in dubio pro reo, para convertirse en un auténtico derecho fundamental de la persona que, de acuerdo al artículo $6^{\circ}$ de la Constitución, vincula a todos los poderes públicos y es de aplicación inmediata" ${ }^{44}$.

Otro de los principios que informa el DIDH y que también se encuentra presente en la Constitución nacional, es el principio de igualdad y no discriminación (artículo 19 No 2 de la Constitución). En un caso referido a discriminación múltiple en contra una mujer indígena, la Corte Suprema concretizó el principio, dándole un contenido particular a la luz de las obligaciones internacionales en materia de prohibición de discriminación y violencia contra las mujeres:

"Que, asimismo, no puede dejar de observarse que la vulneración de derechos en que Gendarmería de Chile ha incurrido en contra de la amparada, como ha sido demostrado, constituye también un acto de discriminación en su condición de mujer, pues el trato recibido por ésta de parte de los agentes estatales desconoció dicho estado de vulnerabilidad y, por ende, de necesidad de protección, en circunstancias que, desde una perspectiva de igualdad de género, se debió haber tomado en consideración la situación particular que experimentaba al acercarse el proceso del parto -más aún en las difíciles circunstancias de salud y de privación de libertad en que éste se desarrolló-, como, por otro lado, la especial significación vital para ella del mismo, sobre todo dentro de la comunidad mapuche a la que pertenece, y el impacto negativo que una aplicación no diferenciada de las normas y reglamentos penitenciarios podía ocasionar en aquella mujer.

43 Corte Suprema. Rol No 46451-2016, 19 de diciembre de 2016.

44 Corte de Apelaciones de La Serena. Rol No 152-2005, 1 de junio de 2005, considerando 7. En un sentido similar, véase: Corte Suprema. Rol No 740-2005, 25 de abril de 2005. 
[...] De ese modo, lo referido contraviene los compromisos pactados en la Convención sobre la Eliminación de todas las formas de Discriminación sobre la Mujer-conocida como CEDAW- suscrita por nuestro país, primer instrumento internacional que recoge el principio mundial para erradicar la discriminación contra la mujer y que confiere derechos a las mujeres frente al Estado, implicando obligaciones de éstos frente a las ciudadanas $[\ldots]^{\prime 25}$.

Vemos de esta manera que, a partir de principios generales que emanan de la Constitución y la legislación, se reconocen derechos específicos y con un contenido concreto a partir de la incorporación del DIDH. Esta concreción es la forma en que se logra una aplicación en casos concretos y de esta forma, dar efectividad de los derechos consagrados internamente.

\subsection{Interpretación de derechos consagrados constitucionalmente y legalmente para dotarlos de contenido y alcance}

Las cláusulas constitucionales se caracterizan por su amplitud e indeterminación. Los derechos fundamentales contenidos con el artículo 19 de la Constitución Política de Chile, e incluso aquellos reconocidos a nivel legal, no escapan de estas características $^{46}$.

La jurisprudencia nacional ha utilizado el DIDH para especificar el alcance de las garantías que componen el proceso racional y justo. Así ha ocurrido con la garantía del juez imparcial, donde se ha recurrido a la jurisprudencia de la Corte IDH para identificar las vertientes de la imparcialidad objetiva y subjetiva ${ }^{47}$. Así ocurre también con el derecho al recurso y la concreción de sus características, tales como la accesibilidad ${ }^{48}$ o el alcance de la doble instancia. Respecto de este último punto, así ha razonado, por ejemplo, la Corte de Apelaciones de Santiago:

45 Corte Suprema. Rol No 92795-2016, de 1 de diciembre de 2016, considerando 14. Acto seguido la Corte Suprema desarrolla ampliamente las obligaciones del Estado en este ámbito, refiriéndose a resoluciones de diversos organismos internacionales, ver: considerando 14 .

46 Desde esta perspectiva "las disposiciones constitucionales de derechos fundamentales se configuran como normas incompletas o abiertas susceptibles de ser 'especificadas' o 'rellenadas' con los contenidos de los tratados de derechos humanos". Cuenca (2012), p. 4.

47 Corte Suprema. Rol No 29359-2014, 29 de enero de 2015 y Corte de Apelaciones de Temuco. Rol No 378-2013, 11 de abril de 2013.

48 Corte Suprema. Rol No 3402-2015, 9 de marzo de 2015. 
"Esto que se viene enunciando es coherente con la regulación legal del recurso de nulidad penal en Chile y tiene correspondencia con el derecho al recurso, integrante del derecho al debido proceso, que consagran tanto nuestra Carta Fundamental como los Tratados Internacionales suscritos y ratificados por nuestro país. Con relación a esto, ha de recordarse que -en un fallo de reciente pronunciamiento, con la particularidad de estar específicamente referido a nuestro recurso de nulidad-, la Corte Interamericana de Derechos Humanos dejó consignado que si bien no estuvo en condiciones de concluir que la causal del artículo 374, letra e) del Código Procesal Penal no cumpla 'con el estándar del recurso eficaz' que consagra la respectiva Convención, puso el acento en que 'la interpretación que los tribunales internos realicen de la referida causal, debe asegurar' el derecho a recurrir de fallo, asumiendo que ello ha de ser expresión de la necesidad de propiciar la 'revisión integral' del mismo (...)”49.

La utilización de la jurisprudencia de la Corte IDH en estos casos refleja, como bien señala Aparicio, que "los criterios para la interpretación constitucional no sólo están contenidos en las propias disposiciones del tratado que se trate, sino que se hallan también en su práctica normativa, es decir, en las decisiones, disposiciones y acuerdos que surjan de los órganos internacionales encargados de darles contenido, asegurar su cumplimiento y, en definitiva, de interpretarles" 50 .En el caso referido, la jurisprudencia de la Corte IDH era además de obligatoria referencia, por tratarse de un caso en el que fue condenado el Estado de Chile (art. 68.1 CADH).

Fuera del ámbito penal, destaca la remisión a los tratados internacionales para dotar de contenido al derecho al fuero maternal en materia laboral51, al derecho a la libertad sindical ${ }^{52}$ y al derecho a huelga ${ }^{53}$.

Aquí el uso del DIDH sirve para fijar el contenido y alcance del derecho a la luz de los estándares internacionales y, de esta forma, se logra dar eficacia al derecho conforme a estándares internacionales, con plena coherencia del sistema normativo interno.

49 Corte de Apelaciones de Santiago. Rol No 427-2015, 10 de abril de 2015, considerando séptimo, que se refiere al fallo condenatorio contra el Estado de Chile en el caso Norín Catrimán vs. Chile (Corte IDH. Caso Norín Catrimán y otros (Dirigentes, miembros y activista del Pueblo Indígena Mapuche) vs. Chile. Fondo, Reparaciones y Costas. Sentencia de 29 de mayo de 2014. Serie C No 279).

50 Aparicio (1989), p. 11.

51 Corte de Apelaciones de Santiago. Rol No 1826-2012, 22 de marzo de 2013; Corte de Apelaciones de Santiago. Rol No 113-2013, 24 de abril de 2013; Corte Suprema. Rol No 19354-2014, 9 de abril de 2015.

52 Corte de Apelaciones de Santiago. Rol No 4344-2006, 19 de julio de 2007 y Corte de Apelaciones de Santiago. Rol No 1701-2007, 31 de marzo de 2008.

53 Corte de Apelaciones de Valdivia. Rol No 20-2007, 10 de julio de 2007 y Corte de Apelaciones de Santiago. Rol No 6885-2007, 31 de octubre de 2009. 


\subsection{Integración de derechos para configurar}

uno nuevo o con un nuevo contenido

A diferencia de la circunstancia anterior, en este caso, como indica Cuenca ${ }^{54}$, se trataría de realizar una conexión entre el DIDH con los derechos constitucionales de manera de "crear" un nuevo derecho, u otorgar a los derechos existentes contenidos novedosos. Estos "nuevos" derechos serían una "expresión de facultades, garantías o posiciones jurídicas no explicitadas constitucionalmente, pero que pueden hacerse derivar de su relación con un derecho fundamental" 55 Respecto a la posibilidad de generar un "contenido nuevo del derecho", se trataría de una "reintegración de derechos" que es lo se produce cuando producto de la integración del DIDH se reconocen nuevas dimensiones de los derechos fundamentales que van emergiendo de acuerdo a la conciencia social y política ${ }^{56}$. Estas nuevas dimensiones pueden implicar, además, la generación de obligaciones adicionales y complementarias al Estado derivadas de la garantía de los derechos constitucionales.

\section{a) Nuevos contenidos y obligaciones}

En cuanto al contenido nuevo de un derecho consagrado constitucionalmente, un ejemplo claro de este uso del DIDH lo encontramos en materia penal, específicamente respecto del derecho de defensa. El artículo 19 No 3 de la Constitución Política de la República consagra el derecho a la defensa técnica en los siguientes términos "toda persona tiene derecho a defensa jurídica en la forma que la ley señale y ninguna autoridad o individuo podrá impedir, restringir o perturbar la debida intervención del letrado si hubiere sido requerida". Este contenido, tal como reconoce la jurisprudencia, debe ser actualizado en atención a los desarrollos del DIDH, pues la Constitución reconoce solo su contenido más elemental:

"Que el derecho a la defensa es conferido por el artículo 19, número 3º, inciso segundo, de la Constitución. Este derecho es también denominado derecho a la

54 Cuenca (2012).

55 SAIZ (1999), p. 82.

56 ReY (1989). Pérez-Tremps lo explica también en los siguientes términos (calificando a este uso como contenido conexo o accesorio): "en otros casos, la invocación del Convenio Europeo y de la jurisprudencia del Tribunal Europeo de Derechos Humanos, o de otros tratados en materia de derechos, no se ha hecho tanto para delimitar el contenido de un derecho o libertad, como para completar éste mediante la incorporación de contenidos conexos o accesorios que no aparecían claros (o ni siquiera aparecían) en el texto constitucional”, Pérez-TREMPS (2016), p. 176. 
defensa letrada o a la defensa técnica. Consiste en la posibilidad de nombrar un abogado y sustituirlo para efectos de contar con una defensa técnica en la tutela o protección de los derechos (...). Pero el derecho a la defensa en el sentido recién expresado, como el derecho a la defensa técnica, constituye sólo la dimensión más elemental de este derecho fundamental. En otras palabras, en el texto constitucional se ha contemplado el contenido más básico de este derecho. En efecto, existen también otros aspectos del derecho fundamental a la defensa que deben ser reconocidos como derechos incluidos en el ordenamiento jurídico chileno. Se trata, por ejemplo, de los derechos reconocidos por el derecho internacional de los Derechos Humanos" 57 .

Se incorporan, mediante la remisión a dictámenes del Comité de Derechos Humanos de Naciones Unidas, otros contenidos al derecho a defensa, tales como el derecho a ser informado de la asistencia letrada, derecho a la asistencia letrada durante el interrogatorio, derecho a comunicarse libre y privadamente con su defensor, derecho a una representación eficaz y derecho a defenderse a sí mismo.

El caso precitado resulta interesante, pues no sólo se hace referencia a tratados sobre derechos humanos para dotar de contenido al derecho a defensa, sino también a resoluciones del Comité de Derechos Humanos de Naciones Unidas. Estas resoluciones se transforman en guías hermenéuticas de referente obligatorio en la medida en que son las resoluciones de los órganos mandatados para velar por el cumplimiento y aplicación de las disposiciones de los tratados ${ }^{58}$.

Siguiendo en materia penal, otro ejemplo es el derecho a un plazo razonable como parte del debido proceso. El plazo razonable es parte de las garantías contempladas explícitamente en el art. 8.1 de la $\mathrm{CADH}^{59}$ y art. 14.1 del PIDCP60,

57 Corte de Apelaciones de Temuco. Rol No 378-2013, 11 de mayo de 2013, considerando 12. En un sentido similar, véase: Corte Suprema. Rol No 3419-2007, 13 de noviembre de 2007 y Corte Suprema. Rol No 6053-2007, 29 de abril de 2008.

58 Su función interpretativa ha sido especialmente destacada por el Comité en relación a las observaciones generales, señalando que éstas expresan la manera en que el Comité entiende conceptualmente el significado de una disposición particular. En este sentido, su contenido interpretativo no obsta al carácter no jurisdiccional de las resoluciones del órgano, véase TRINIDAD, 2009.

59 Artículo 8.1: “Toda persona tiene derecho a ser oída, con las debidas garantías y dentro de un plazo razonable, por un juez o tribunal competente, independiente e imparcial, establecido con anterioridad por la ley, en la sustanciación de cualquier acusación penal formulada contra ella, o para la determinación de sus derechos y obligaciones de orden civil, laboral, fiscal o de cualquier otro carácter".

60 Artículo 14.2.c: "c) A ser juzgado [dentro proceso penal] sin dilaciones indebidas". 
ambas aplicables en Chile ${ }^{61}$. Por su parte, en el derecho de origen nacional, si bien el derecho a un plazo razonable no se encuentra consagrado explícitamente en el texto constitucional, sí se puede desprender del numeral $3^{\circ}$ del artículo 19. En este sentido, la Corte Suprema ha señalado:

"No obstante, no es posible soslayar la circunstancia cierta de que tal precepto encierra un concepto jurídico indeterminado, careciendo de baremos específicos dentro de los cuales se encuadre su aplicación, esto es, no contiene la determinación de lo que debe entenderse como un plazo razonable. En ese sentido, y ante la detección de esta carencia, la aplicación del principio queda entregada a la determinación del intérprete, quien ha de tener presente las circunstancias del caso puesto que debe ponderar los hechos objetivos de la sustanciación del proceso, a fin de adquirir convicción en torno a la existencia de elementos que permitan entender que ha tenido lugar una dilación inexcusable, actividad para la cual deben considerarse aspectos tales como la complejidad del asunto, diligencia de las autoridades judiciales, y actividad procesal del interesado, tal como ha señalado el propio Sistema Americano de Protección a los Derechos Humanos (Caso Genie Lacayo vs. Nicaragua, Sentencia de 29 de enero de 1997; C.V.A.V.P., Sentencia de 26 de septiembre de 2006 y C.E.Z. vs. Colombia, Sentencia de 4 de julio de 2007)"62.

Otro ejemplo de integración de contenidos, lo encontramos respecto del derecho a indemnización por error judicial, respecto del cual la Corte Suprema ha entendido que por integración de las normas internacionales sobre derechos humanos, comprende también la indemnización en casos de auto de procesamiento $^{63}$ o prisión preventiva ${ }^{64}$ dictada erróneamente, y que no se extiende únicamente a casos de condenas firmes. En materia laboral, se puede destacar la interpretación progresiva de las causales que dan origen a la acción de tutela de derechos fundamentales por discriminación, donde se ha entendido que el concepto de discriminación del Código del Trabajo no es taxativo a la luz del DIDH e incorpora causales tales como la prohibición de discriminación por discapacidad:

61 En lo pertinente a este informe, la Corte Suprema ha señalado: “(...) los preceptos de la Convención Americana sobre Derechos Humanos y, más precisamente, la garantía de ser juzgado dentro de un plazo razonable, tienen aplicación directa por estar incorporada al ordenamiento jurídico nacional", Corte Suprema. Rol No 11872-2014, 28 de mayo de 2015, considerando 5.

62 Corte Suprema. Rol No 1187-2014, 28 de mayo de 2015.

63 Corte Suprema. Rol No 5411-2010, 11 de agosto de 2011.

64 Corte Suprema. Rol No 4921-2014, 9 de junio de 2014; Corte Suprema. Rol No 22356-2014, 20 de abril de 2015 y Corte Suprema. Rol No 1579-2015, 8 de julio de 2015. 
"Que, de este modo, de entenderse que la tutela otorgada por el legislador al trabajador víctima de actos discriminatorios durante la vigencia de la relación laboral -de conformidad a lo previsto en el artículo 485 inciso segundo del Código del Trabajo-, se encuentra limitada únicamente a aquellos criterios expresamente previstos por el artículo $2^{\circ}$ del Código del Trabajo, como lo ha hecho el tribunal recurrido, importaría concluir que nuestro procedimiento de tutela laboral protege sólo parcialmente el derecho a la no discriminación, excluyendo actuaciones basadas en otros criterios, los no previstos expresamente en la norma laboral, que el legislador nacional sí ha prohibido por otras vías de mayor rango legal, como son la propia Constitución Política de la República y el ya citado Convenio OIT No 111 de 1958, al cual le resulta plenamente aplicable lo dispuesto en el artículo $5^{\circ}$ inciso segundo de la Carta Fundamental"65.

Una nueva manifestación de la integración de contenidos a partir de la incorporación de la norma internacional, lo constituyen aquellos casos donde el DIDH otorga lineamientos específicos para la actuación de la autoridad pública en garantía de derechos constitucionales. Se trata, por ejemplo, de la incorporación de obligaciones derivadas de la prohibición de la tortura o de obligaciones específicas respecto de grupos en situación de discriminación, como son los niños y niñas y pueblos indígenas. Un ejemplo del primer caso lo constituyen aquellos casos en que las Cortes nacionales incorporan las obligaciones de la Convención Internacional para Prevenir y Sancionar la Tortura, estableciendo mandatos preventivos que consisten en la adecuación de los protocolos internos para prevenir la tortura en los recintos penitenciarios ${ }^{66}$. El segundo caso, por su parte, se da cuando las Cortes mandatan a las policías a ajustar sus protocolos de uso de la fuerza en consideración a las obligaciones que impone el Convenio 169 de la $\mathrm{OIT}^{67}$ o la Convención sobre Derechos

65 Corte Suprema. Rol No 23808-2014, 5 de agosto de 2015, considerando séptimo.

66 Se ha dispuesto, por ejemplo: "Gendarmería de Chile deberá adecuar sus protocolos de actuación así como sus actuaciones propiamente tales, en forma especial a lo que dispone su normativa interna y particularmente a lo que dispone la Convención contra la Tortura, aplicando con racionalidad y proporcionalidad, cuando corresponda, las herramientas que establece su normativa interna en cuanto al uso de la fuerza y elementos de seguridad y persuasión”. (Corte de Apelaciones de Concepción. Rol No 97-2015, 8 de junio de 2015. En el mismo sentido: Corte de Apelaciones de Valdivia. Rol No 8-2013, 13 de marzo de 2013; Corte de Apelaciones de Antofagasta. Rol No 68-2013, 7 de diciembre de 2013 y Corte de Apelaciones de Concepción. Rol No 78-2015, 4 de mayo de 2015.

67 Corte de Apelaciones de Temuco. Rol No 342-2011, 16 de diciembre de 2011; Corte de Apelaciones de Temuco. Rol No 1136-2011, 21 de diciembre de 2011; Corte de Apelaciones de Temuco. Rol No 449-2012, 5 de agosto de 2012 y Corte Suprema. Rol No 5441-2012, 20 de julio de 2012. 
del Niño ${ }^{68}$. Asimismo, respecto de los pueblos indígenas, se han incorporado obligaciones específicas para garantizar el derecho a la consulta previa ${ }^{69}$.

\section{b) Nuevos derechos}

En cuanto a la integración para configurar nuevos derechos, destaca principalmente la jurisprudencia referida al derecho a la identidad. Este derecho, que no se encuentra reconocido explícitamente en la Constitución, ni tampoco en los tratados internacionales sobre derechos humanos, ha sido construido por la jurisprudencia nacional a través de una lectura conjunta de las disposiciones constitucionales (artículo 5.2 de la Constitución y concepto de dignidad humana) y de tratados internacionales (Convención sobre Derechos del Niño, artículos 7 y 8, y artículo 18 de la Convención Americana sobre Derechos Humanos) y ha permitido extender las acciones de filiación en aquellos casos en que se encontraba limitada ${ }^{70}$. Asimismo, esto ha permitido, por ejemplo, solucionar problemas que se generan con ocasión de la indefensión en que se encuentran las personas en situación migratoria irregular en Chile en relación a sus hijos/as:

"En esas condiciones fácticas y normativas [artículos 3, 7 y 18 Convención Derechos del Niño] la menor ALMD tiene derecho a conocer su identidad y a reclamar de su padre derechos, así como éste los tiene respecto de ella, al mismo tiempo que obligaciones, todo lo cual no es posible de concretar, atendida la situación migratoria de su padre en Chile, en particular la imposibilidad de poder contar con la documentación que le permita efectuar los actos a los que el Código Civil reconoce validez para efectuar el reconocimiento.

68 Corte de Apelaciones de Temuco. Rol No 342-2011, 16 de diciembre de 2011; Corte de Apelaciones de Temuco. Rol No 604-2012, 3 de septiembre de 2012; Corte de Apelaciones de Temuco. Rol No $982-$ 2013, 31 de enero de 2014 y Corte de Apelaciones de San Miguel. Rol No 32-2014, 3 de marzo de 2014.

69 En esta materia la producción jurisprudencial de las Cortes de Apelaciones ha sido intensa. Sólo a modo de ejemplo, véase: Corte de Apelaciones de Temuco. Rol No 1705-2009, 21 de enero de 2010; Corte Suprema. Rol No 258-2011, 13 de junio de 2011; Corte Suprema. Rol No 10090-2011, 22 de marzo de 2012; Corte de Apelaciones de Temuco. Rol No 454-2012, 3 de junio de 2012 y Corte de Apelaciones de Temuco. Rol No 545-2010, 15 de diciembre de 2012. Un estudio jurisprudencial completo sobre esta tendencia se puede encontrar en NASH (2014).

70 Véase, Corte Suprema. Rol No 4325-2006, 29 de enero de 2007; Corte de Apelaciones de Concepción. Rol No 3620-2004, 27 de marzo de 2008; Corte de Apelaciones de San Miguel. Rol No 193-2010, 14 de junio de 2010; Corte de Apelaciones de Santiago. Rol No 2444-2009, 15 de junio de 2010; Corte de Apelaciones de Talca. Rol No 986-07, 3 de noviembre de 2010. 
"Lo anterior conduce a acoger el recurso presentado sólo en cuanto, de acuerdo a la normativa nacional e internacional citada, la imposibilidad de obtener el reconocimiento de la paternidad en relación a la menor AMLD, resulta ilegal, vulnerando el derecho a la integridad psíquica y física de la referida menor al no permitir la concreción de su derecho a la identidad, e impedir -por cuestiones administrativas-el establecimiento de una filiación, de la que derivan múltiples derechos, tanto para ella como para su padre" 71 .

Por otra parte, mediante la técnica de la integración normativa, también se ha realizado un reconocimiento implícito al derecho a la identidad de género, permitiendo el cambio de sexo registral para personas transgénero. Así lo ha expresado, por ejemplo, la Corte de Apelaciones de Arica:

"Que, en este orden de ideas cabe señalar que aun cuando la Constitución Chilena no reconozca, en su texto, el derecho a la identidad, ello no implica desconocer su naturaleza de tal y por lo mismo se le brinde una adecuada protección, atendida su estrecha vinculación con la dignidad humana y porque se encuentra protegido expresamente en diversos tratados internacionales ratificados por Chile y vigentes en nuestro país. Esto adquiere una vital importancia, cuando se trata de personas que por tratarse de una minoría, el reconocimiento de su identidad resulta determinante para el efectivo ejercicio de todos sus derechos"72.

De esta forma, vemos cómo mediante la reintegración normativa entre el DIDH y el derecho interno surgen también nuevos derechos que dan respuestas a las necesidades de protección de grupos especialmente vulnerables de la población, como son los niños/as y las personas transgénero/transexuales.

\subsection{Llenar lagunas para el ejercicio jurisdiccional}

El DIDH también ha sido utilizado por los tribunales superiores de justicia para dar respuesta a situaciones que no se encuentran previstas en el derecho interno. Considerando el mandato de inexcusabilidad de los tribunales superiores de justicia, los tribunales nacionales han incorporado derechos al catálogo constitucional que no se encuentran contemplados. Así ha ocurrido, por ejemplo, con el derecho al recurso:

71 Corte de Apelaciones de Santiago. Sentencia Rol No 36243-2014, 7/10/14, considerandos 10 y 11.

72 Corte de Apelaciones de Arica. Rol No 189-2016, 5 de agosto de 2016, considerando 6. En el mismo sentido: Corte de Apelaciones de Iquique. Rol No 496-2014, 26 de noviembre de 2014; Corte de Apelaciones de Santiago. Rol No 13001-2015, 29 de marzo de 2016 y; Corte de Apelaciones de Santiago. Rol No 12571-2015, 27 de enero de 2016. 
"Que en numerosos tratados internacionales suscritos por Chile, ratificados y actualmente vigentes, y que tal como lo preceptúa el artículo $5^{\circ}$ de nuestra Constitución Política, constituyen y forman parte de las leyes de la República, también se considera este derecho a tener un recurso en contra de las sentencias condenatorias o absolutorias en materia penal (...)

"Si bien este derecho no se encuentra expresamente contemplado en nuestra carta fundamental, resulta igualmente obligatorio porque los pactos mencionados [CADH y Pacto Internacional Derechos Civiles y Políticos] fueron ratificados por Chile y se hallan actualmente vigentes, en virtud de lo prescrito en el artículo $5^{\circ}$ de la Constitución Política de la República”73.

Este fenómeno ocurre también con el caso de los derechos económicos, sociales y culturales (DESC). Al ser la Constitución chilena una carta fundamental de raigambre neoliberal, la consagración de los DESC se encuentra limitada, tanto respecto a los derechos que son reconocidos, así como respecto a las garantías jurisdiccionales. En este sentido, el DIDH se ha utilizado para reconocer, por ejemplo, la existencia del derecho al agua ${ }^{74}$, o del derecho a una vivienda digna ${ }^{75}$. Lo relevante, es que en estos casos se han utilizado las Observaciones Generales del Comité DESC para dar un contenido autónomo y específico a estos derechos. Sin embargo, desde la perspectiva procesal, en ambos casos la protección jurisdiccional sólo se ha dado reconociendo la vinculación entre estos derechos y algún derecho de tipo civil y político, como es el derecho a la vida o integridad física ${ }^{76}$.

\subsection{Inaplicar normas que incumplen las obligaciones internacionales del Estado}

Este es el uso más intenso del DIDH en el ámbito interno. Pese a no encontrarnos en sede de jurisdicción constitucional (es decir, en un proceso de inaplicabilidad por inconstitucionalidad o frente a una acción de inconstitucionalidad),

73 Corte Suprema. Rol No 6053-2007, 29 de abril de 2008 El destacado es propio. En el mismo sentido: Corte Suprema. Rol No 5179-2008, 18 de noviembre de 2008.

74 Corte de Apelaciones de Santiago. Rol No 10140-2012, 28 de junio de 2012; Corte de Apelaciones de San Miguel. Rol No 1106-2015, 11 de diciembre de 2015; Corte de Apelaciones de San Miguel. Rol No 2052-2015, 14 de abril de 2016 y, Corte de Apelaciones de Temuco. Rol No 6345-2016, 21 de diciembre de 2016.

75 Corte de Apelaciones de Temuco. Rol No 8828-2013, 21 de julio de 2014.

76 NASH y NúNÉEZ (2015). 
las Cortes de Apelaciones y la Corte Suprema han utilizado el DIDH para dejar de aplicar una norma incompatible con las obligaciones internacionales del Estado, de manera de cumplir con el mandato convencional 77 . Esto se ha dado principalmente respecto de casos vinculados con violaciones masivas y sistemáticas a los derechos humanos ${ }^{78}$. Se trata, en definitiva, de corregir anteriores interpretaciones de la normativa interna que están enfrentadas o no resultan del todo adecuadas a la luz de los avances del derecho internacional79.

En esta materia se han usado tanto los tratados internacionales, como la jurisprudencia de la Corte IDH. Se destacan tres aspectos: inaplicación del Decreto Ley de Amnistía, inaplicación de la prescripción en materia penal e inaplicación de las normas de prescripción civil respecto de indemnizaciones.

Un hito en la materia es el denominado "Caso Sandoval' 80 donde la Corte Suprema se refirió a la obligación del Estado de Chile de proscribir la impunidad en casos referidos a violaciones masivas y sistemáticas a los derechos humanos ${ }^{81}$. En este sentido, la jurisprudencia nacional ha hecho referencia a la existencia de una Constitución material que incorpora estas obligaciones para el Estado, por mandato del artículo $5^{\circ}$ de la Constitución ${ }^{82}$.

Sobre otras fuentes de derecho internacional, destaca particularmente lo asentado en el denominado "Caso Molco" 83 , donde para resolver la imprescriptibilidad

77 La posibilidad de conocer y fallar en este sentido se explica por la posibilidad que presentan estos casos de realizar una interpretación armónica de la legislación aplicando directamente la norma internacional (cuando esta es lo suficientemente específica para permitir su aplicación directa).

78 En esta materia, se revisaron 184 sentencias dictadas en el período 2005-2014. De las cuales 58 corresponden a sentencias dictadas por Cortes de Apelaciones y 126 a sentencias dictadas por la Corte Suprema. De las 184 sentencias revisadas, 75 de ellas hacen referencia al DIDH.

79 Cuenca (2012).

80 Corte Suprema. Rol No 517-2004, 17 de noviembre de 2004.

81 Corte Suprema. Rol No 517-2004, 17 de noviembre de 2004, considerando 35.

82 "En definitiva los derechos humanos asegurados en un tratado se incorporan al ordenamiento jurídico interno, formando parte de la Constitución material adquiriendo plena vigencia, validez y eficacia jurídica, no pudiendo ningún órgano del Estado desconocerlos y debiendo todos ellos respetarlos y promoverlos, como asimismo, protegerlos a través del conjunto de garantías constitucionales destinadas a asegurar el pleno respeto de los derechos. Esta obligación no sólo deriva del mentado artículo $5^{\circ}$, sino también del $1^{\circ}$, incisos primero y cuarto, y 19 , № $26^{\circ}$, de la Carta Magna y de los mismos tratados internacionales, entre éstos del artículo $1^{\circ}$ común a los Cuatro Convenios de Ginebra, que establece el deber de los Estados Partes de respetar y hacer respetar el derecho internacional humanitario [...]". Corte Suprema. Rol No 1528-2006, 25 de enero de 2008, considerando 43.

83 Corte Suprema. Rol No 559-2004, 13 de diciembre de 2006. 
de los crímenes de lesa humanidad se hizo mención a los principios de ius cogens y a la jurisprudencia de la Corte IDH.

Asimismo, en otro hito de recepción sustancial del DIDH en la materia, la Corte Suprema se ha referido a la obligación del Estado de reparar a las víctimas de violaciones de derechos humanos ${ }^{84}$. Para ello, argumenta sobre la base de la Convención de Viena de Derecho de los Tratados:

"Que, la normativa internacional aplicable en la especie, por mandato constitucional, propende a la reparación integral de las víctimas, lo que incluye el ámbito patrimonial -de conformidad a los Convenios y Tratados celebrados por Chile- que por disposición constitucional le son vinculantes, como ocurre v. gr., y entre otros, con la propia Convención de Viena sobre Derecho de los Tratados, el que se encuentra vigente en nuestro país desde el 27 de enero de 1980, la que establece en su artículo 27 que el Estado no puede invocar su propio derecho interno para eludir sus obligaciones internacionales, pues de hacerlo comete un hecho ilícito que compromete la responsabilidad internacional del Estado" 85 .

Decíamos que en estas materias se había dado un uso intenso al DIDH, pero también encontramos ejemplos de inaplicación de normativa nacional por ser contraria a las obligaciones internacionales del Estado en derecho de familia. Destaca particularmente la inaplicación de normas procesales que impiden la libre investigación de la identidad o la determinación de la filiación ${ }^{86}$ o la inaplicación de normas que establecen diferencias entre hombres y mujeres en el Código Civil chileno ${ }^{87}$.

Por otra parte, en el ámbito de la justicia militar, no se han aplicado las normas que impiden la revisión del fallo, por aplicación de las normas internacionales que consagran el derecho al recurso ${ }^{88}$.

En el área de la justicia penal juvenil, se ha dejado sin aplicación la sanción de incorporación de la huella genética del adolescente en un registro nacional,

84 Véase, entre otras: Corte Suprema. Rol No 519-2013, 18 de julio de 2013; Rol No 5831-2013, 10 de junio de 2014; Rol No 3841-2012, 19 de junio de 2013; Rol No 6308-2007, 8 de septiembre de 2008 y Rol No 5132-2008, 27 de enero de 2009.

85 Corte Suprema. Rol No 6-2009, 15 de marzo de 2010, considerando 25.

86 Ver, por ejemplo, Corte de Apelaciones de Rancagua. Rol No 23-2010, 16 de marzo de 2010 y Corte Suprema. Rol No 3784-2013, 24 de septiembre de 2013.

87 Corte de Apelaciones de Punta Arenas. Rol No 116-2011, 20 de enero de 2012.

88 Corte Suprema. Rol No 25491-2014, 27 de noviembre de 2014 y Corte Suprema. Rol No 3581-2015, 7 de mayo de 2015. 
por ser contraria al artículo 40.1 de la Convención sobre Derechos del Niño ${ }^{89}$, así como también se ha restringido la utilización de las condenas previas como agravantes en casos de adolescentes, por aplicación incluso de normas que no son tratados, como las Reglas de Beijing ${ }^{90}$.

Finalmente, ejerciendo el control de convencionalidad ${ }^{91}$ encontramos también sentencias que -por aplicación de los fallos condenatorios al Estado de Chile- modifican su jurisprudencia, como es el caso de los fallos que restringen la aplicabilidad del fuero militar ${ }^{92}$.

En definitiva, las normas del DIDH se han utilizado como parámetro para determinar la inaplicación de las normas internas contrarias a las obligaciones internacionales, de manera de dar coherencia al ordenamiento jurídico.

\subsection{Limites de los derechos fundamentales}

Finalmente, otro uso que se le ha dado al DIDH ha sido la importación de sus mecanismos de determinación de límites de los derechos desde la perspectiva normativa o argumentativa93.

Desde la perspectiva normativa destacan principalmente casos referidos al derecho de libertad de expresión. En este sentido, se ha utilizado la jurisprudencia interamericana para dotar de contenido a conceptos abstractos tales como "interés público":

89 Corte Suprema. Rol No 559-2015, 8 de enero de 2014; Corte de Apelaciones de Temuco. Rol No 8882014, 21 de octubre de 2014.

90 Corte de Apelaciones de Santiago. Rol No 728-2010, 14 de mayo de 2010; Corte de Apelaciones de La Serena. Rol No 262-2010, 27 de noviembre de 2010; Corte de Apelaciones de Valparaíso. Rol No 15262013, 10 de diciembre de 2013; Corte de Apelaciones de Temuco. Rol No 888-2014, 21 de octubre de 2014; Corte de Apelaciones de Temuco. Rol No 86-2015, 20 de febrero de 2015. Aunque éste no ha sido un aspecto pacífico en la jurisprudencia, véase: Corte de Apelaciones de Santiago. Rol No 671-2013, 7 de mayo de 2013 y Corte de Apelaciones de Concepción. Rol No 671-2012, 21 de diciembre de 2013.

91 El control de convencionalidad (en el ámbito interno), consiste en el deber de los/as jueces/zas, órganos de la administración de justicia y demás autoridades públicas, de realizar un examen de compatibilidad entre los actos y normas nacionales y la $\mathrm{CADH}$, sus protocolos adicionales, la jurisprudencia de la Corte IDH y demás instrumentos del sistema interamericano (Ferrer Mac-Gregor (2012). Su base normativa se encuentra en las normas del Derecho Internacional Público (artículos 26 y 27 de la Convención de Viena) y en el ámbito interamericano en los artículos 1.1, 2 y 29 de CADH. En el caso de Chile ha tenido una aplicación progresiva en el ámbito constitucional y en el ámbito de la justicia ordinaria, fundando los tribunales su aplicación en el artículo $5^{\circ}$ inc. 2 de la Constitución (Núnez, 2015).

92 Véase, por ejemplo, Corte de Apelaciones de San Miguel. Rol No 1745-2012, 18 de diciembre de 2012.

93 Este último se trata de aquellos casos en que lo que se importa es el "test" o razonamiento a seguir en el juicio, Pérez-Tremps, 2016, p. 176. 
"Que, valorando los antecedentes proporcionados de acuerdo a las reglas de la sana crítica, se concluye para efectos de esta sede cautelar, que la información -imágenes, textos y voces- fue transmitida por el medio de comunicación social recurrido, amparado en la circunstancia de existir un 'interés público', de acuerdo a la noción contemplada en el referido artículo 30, que regula lo que debemos entender por dicho interés, preceptuando en su literal b) que se consideran como hechos de interés público de una persona: 'Los realizados en el ejercicio de una profesión u oficio y cuyo conocimiento tenga interés público real'.

"El alcance de esta noción de interés público real ha sido muy bien explicada por la Corte Interamericana de Derechos Humanos cuando sostiene: 'en cuanto al carácter de interés público, en su jurisprudencia la Corte ha reafirmado la protección a la libertad de expresión respecto de las opiniones o informaciones sobre asuntos en los cuales la sociedad tiene un legítimo interés de mantenerse informada, de conocer lo que incide sobre el funcionamiento del Estado, o afecta derechos o intereses generales o le acarrea consecuencias importantes' (Corte Interamericana de Derechos Humanos, sentencia de 29 de noviembre de 2011, caso Fontevecchia y D'Amico vs. Argentina).

"Por los motivos expresados, no se divisa en la actividad informativa reclamada, según los antecedentes proporcionados, quebrantamiento de la normativa legal, inserta que está ella en el ejercicio de la libertad de informar que faculta a los medios de comunicación social para transmitir las noticias cuestionadas, en la especie, basados en la existencia de un interés público real en que la ciudadanía conozca de una determinada información" 94 .

Asimismo, la normativa de la $\mathrm{CADH}$ ha sido utilizada para determinar la improcedencia de la censura previa en materia de libertad de expresión, incorporando el estándar de las responsabilidades ulteriores ${ }^{95}$.

Un caso particularmente importante destaca en el ámbito penitenciario. Recientemente la Corte Suprema resolvió el análisis de legitimidad de la restricción del derecho al sufragio de personas privadas de libertad, tomando como parámetro el DIDH:

"Que con el mérito de lo expuesto [artículo 25 Pacto Internacional de Derechos Civiles y Políticos y artículo 23 de la CADH], se puede concluir que el actuar de

94 Corte de Apelaciones de Santiago. Rol No 66458-2014, 18 de noviembre de 2014, considerando 5. En el mismo sentido: Corte Suprema. Rol No 21499-2014, 8 de octubre de 2014 y Corte de Apelaciones de San Miguel. Rol No 334/2015, 9 de julio de 2015.

95 Corte de Apelaciones de Santiago. Rol No 38520-2014, 5 de septiembre de 2014 y Corte de Apelaciones de Santiago. Rol No 100344-2015, 7 de marzo de 2016. 
las recurridas es ilegal, toda vez que conforme se ha expuesto precedentemente éstas se encuentran obligadas tanto por la normativa interna como por los tratados internacionales suscritos por Chile a velar por el oportuno y adecuado ejercicio del derecho a sufragio de los recurrentes, quienes mantienen incólume su derecho a sufragio como los demás ciudadanos y sin embargo no pueden ejercerlo vulnerándose la garantía de igualdad de trato, motivo por el cual el recurso de protección debe ser acogido" 96 .

En cuanto al razonamiento o metodología para analizar los asuntos que se plantean en materia de límites de los derechos fundamentales (perspectiva argumentativa), destacan casos vinculados a las facultades estatales para la expulsión de inmigrantes. En estos casos el DIDH cumple dos papeles: estándar de razonamiento (análisis de la proporcionalidad de la medida de expulsión), así como elemento sustantivo para analizar la proporcionalidad de la medida. En este sentido, el DIDH se utiliza para fundamentar la existencia del derecho a la protección de la familia y de los derechos del niño a permanecer con sus padres, lo que permitiría plantear que la medida de expulsión es desproporcionada en atención a los derechos en juego ${ }^{97}$.

\subsection{Otras perspectivas de utilización del DIDH}

Más allá de los usos estudiados hay otros que se encuentran abordados de manera incipiente en Chile y que, a diferencia de experiencias comparadas en América Latina ${ }^{98}$, no han sido profundizadas. Se trata, fundamentalmente, de la utilización de cláusulas generales de interpretación que están contenidas en los tratados de derechos humanos, es decir, la "utilización estable de determinados parámetros para fijar la operatividad de una cláusula abierta" 99 .

Estos principios pueden ser encontrados en los diferentes tratados sobre derechos humanos ratificados por Chile, es el caso de los criterios de justificabilidad de la restricción de derechos, del alcance del principio de igualdad y de la prohibición de discriminación, de los principios de interpretación en materia de derechos económicos, sociales y culturales (contenido mínimo esencial, razona-

96 Corte Suprema. Rol No 87743-2016, 2 de febrero de 2017, considerando 9.

97 Véase, por ejemplo, Corte Suprema. Rol No 2174-2013, 18 de mayo de 2013; Corte de Apelaciones de Santiago. Rol No 19-2013, 21 de enero de 2013 y Corte Suprema. Rol No 10425-2014, 7 de mayo de 2014.

98 NASH y NúŃEZ (2017).

99 Aparicio (1989), p. 17. 
bilidad de las medidas adoptadas para satisfacer derechos, prioridad de los grupos más vulnerables) ${ }^{100}$; y por sobre todo, del principio pro persona, consagrado en el artículo 29 de la CADH ${ }^{101}$.

\section{6. ¿POR QUÉ SE JUSTIFICAN ESTOS USOS?}

Una objeción que se encuentra presente de manera permanente tanto en el ámbito académico ${ }^{102}$, como en el ámbito jurisdiccional ${ }^{103}$, es que la referencia al DIDH puede tornarse innecesaria, pues la aplicación de derechos fundamentales puede ser resuelta con la normativa constitucional, la que resultaría suficiente para dar respuesta a los conflictos ${ }^{104}$.

De manera general, frente a estas objeciones puede destacarse que al asumirse una teoría de la interpretación intermedia (la teoría más difundida en la actualidad) ${ }^{105}$, se puede sostener que no existe ninguna norma constitucional o

100 COURTis (2012).

101 Véanse las excepciones contenidas en las siguientes sentencias: Corte de Apelaciones de Concepción. Rol No 26-2014, 2 de marzo de 2014 y Corte de Apelaciones de Temuco. Rol No 46-2013, 27 de febrero de 2013.

102 Esto es lo que la doctrina denomina interpretación neutralizante del DIDH. Así lo expresa Sudre respecto al Convenio Europeo: "stratégie de contournement ou d' évitement, visant à 'neutraliser' l'interprétation européenne en créant, par une interprétation un peu 'forcée' du droit national, voire par une réécriture de la loi, un rapport d'adéquation entre le droit interne et1la norme européenne”. SUDRE (2004), p. 110. El estudio de la crítica de Sudre y sus consecuencias ha sido desarrollado en Nogueira (2013).

103 Nos referimos a aquellos casos donde los tribunales de justicia señalan directamente que no es necesario recurrir a la legislación internacional para resolver el conflicto, como por ejemplo, en los votos de los Ministros Valdés y Egnem que en un caso referido a la apatridia de un niño "consideran innecesaria la invocación de la legislación internacional que se contiene en el motivo octavo, pues en su concepto el ordenamiento nacional brinda la solución adecuada y justa al problema planteado, como lo demuestran las restantes consideraciones del presente fallo". Corte Suprema. Rol No 7580-2012, 22 de enero de 2013. En el mismo sentido: Corte Suprema. Rol No 9168-2013, 11 de marzo de 2013; sentencia de 27 de abril de 2013, Rol No 300-2013, 14 de enero de 2014; Rol No 10897-2013; 24 de marzo de 2014; Rol No 16044-2013. Un análisis sobre esta interpretación de la Corte Suprema, en: NúñEZ (2015).

104 Tal como bien analiza Cuenca, suele decirse que las herramientas interpretativas que ofrece al DIDH son estériles, pues por su redacción en términos amplios y abstractos, "los textos internacionales no suelen ofrecer mayor claridad y precisión que nuestra norma constitucional en la regulación de los derechos fundamentales por lo que la ayuda que de hecho prestan en su interpretación es escasa”. Cuenca (2012), p. 18.

105 Guastini la denomina el neo-cognitivismo contemporáneo, GUASTINI (2010), p. 40. Esta teoría no niega la vaguedad del lenguaje normativo y que si bien hay casos "fáciles" y casos "difíciles", incluso en los casos fáciles hay un nivel de interpretación en la propia determinación de sus características. 
legal "suficientemente clara" y su ejercicio de aplicación requiere siempre de una interpretación no sólo explicativa de su contenido, sino también que la dote de ese contenido ${ }^{106}$. Además, si se asumiera una concepción restringida de la interpretación (en la cual sólo se recurriría al DIDH en caso de duda), se plantea el problema de dejar en manos del intérprete la elección de cuándo recurrir a los tratados sobre derechos humanos ${ }^{107}$, existiendo el riesgo de hacer incurrir al Estado en responsabilidad internacional.

Por otra parte, como hemos visto en los ejemplos precedentes, el DIDH como parte del sistema normativo interno, es imperativo. Como destaca Saiz, a propósito del análisis del artículo 10.2 de la Constitución española, "el intérprete de los derechos fundamentales ha de tener presente toda la Constitución; desde luego sus disposiciones sustantivas y también siempre, aquella que le impone acudir a ciertas fuentes iusinternacionales para la exégesis de tales derechos"108. En el caso chileno, la obligatoriedad de tomar en consideración el estándar internacional viene dada por el artículo $5^{\circ}$ inc. $2^{\circ}$ de la Constitución, que al constituir una norma de reenvío que permite afirmar la existencia de un "bloque constitucional de derechos", obliga al intérprete a realizar una interpretación sistemática del ordenamiento y es, precisamente, en la sistematicidad que descansa la obligatoriedad de la utilización del estándar internacional como criterio interpretativo en un sentido amplio.

En una lógica argumentativa del Derecho, no basta el resultado. Para lograr plena legitimidad de una resolución judicial, es relevante que en toda resolución judicial entregue sus fundamentos y explique de qué forma aplicó el sistema normativo en su totalidad (derecho de origen interno y derecho de origen internacional). Así, el tribunal no sólo resuelve, sino que convence.

Además, desde la perspectiva normativa que justifica el uso del DIDH, hay razones prácticas y jurídicas que justifican su aplicación en el sentido planteado.

\subsection{Mejoran la efectividad de los derechos consagrados internamente}

La utilización del DIDH en el ámbito interno mejora la efectividad de los derechos consagrados internamente. Permite o facilita que los derechos consagrados

\footnotetext{
106 SAIZ (1999).

107 Ezquiaga (2016).

108 SAIZ (1999), p. 210.
} 
internamente puedan cumplir con su objeto y fin en cada caso concreto, pues su incorporación obliga a la judicatura a interpretar las normas buscando aquella interpretación que permita a cada persona o grupo protegido por las mismas, su pleno goce y ejercicio.

Otro aspecto relevante de la mejora en la efectividad de los derechos consagrados internamente tiene que ver con aquellos espacios que la normativa interna no aborda o aborda de manera imperfecta. La "ayuda" del DIDH es fundamental cuando se trata de instrumentos internacionales "especializados" o "temáticos", pues éstos "contienen formulaciones más concretas, detalladas y precisas que las contenidas en nuestro texto constitucional" 109 . Esto es claro, por ejemplo, con el uso del Convenio 169 de la OIT para incorporar obligaciones adicionales al derecho de consulta previa consagrado a nivel interno, dando efectividad al derecho a la participación y a la igualdad ante la ley consagrados constitucionalmente ${ }^{110}$.

Asimismo, la incorporación del DIDH juega un rol fundamental en la dinamización del sistema jurídico. En muchas ocasiones, el DIDH se adecua de mejor manera a los tiempos, proponiendo soluciones concretas a los conflictos que se presentan. Así ocurre como vimos con el derecho a la identidad de género o las interpretaciones referidas a la libertad de circulación en el contexto de un mundo globalizado. En efecto, el recurso a los tratados es útil cuando se trata de instrumentos posconstitucionales que no pudieron ser tenidos en cuenta en la redacción constitucional ${ }^{111}$.

\subsection{Permite el cumplimiento de los compromisos internacionales}

Al suscribir los tratados internacionales en materia de derechos humanos, los Estados se obligan a adoptar todas las medidas necesarias para su cumplimiento de buena fe ${ }^{112}$. Dentro de estas medidas estatales está la obligación de adoptar medidas jurisdiccionales, esto es, que los tribunales adopten medidas tanto en la tramitación de los casos como en la resolución sustantiva de los mismos a la luz

109 Cuenca (2012), p. 18.

110 Además de los casos citados en el apartado anterior, en esta materia se puede consultar el estudio de NASH, et al. (2014).

111 Cuenca (2012).

112 Convención de Viena de Derecho de los Tratados. Artículo 26 "Pacta sunt servanda. Todo tratado en vigor obliga a las partes y debe ser cumplido por ellas de buena fe". 
del contenido y alcance de los derechos humanos consagrados en los instrumentos internacionales ${ }^{113}$.

En los ejemplos analizados, en este ámbito destacan particularmente los casos referidos a la inaplicación de la norma interna, que en el razonamiento de las Cortes se justifica precisamente en las obligaciones internacionales del Estado. Así ocurre, como vimos, con la inaplicación de normas que favorecen la impunidad de las violaciones masivas y sistemáticas a los derechos humanos. La omisión del ejercicio del control de convencionalidad en el ámbito de competencias del juzgador trae consigo el riesgo de hacer incurrir al Estado en responsabilidad internacional, la magistratura nacional es la primera llamada a garantizar los derechos y ello precisa interpretaciones que se conformen a las obligaciones internacionales ${ }^{114}$.

\subsection{Permite una interpretación \\ que le da coherencia al sistema normativo interno}

En un sistema codificado como lo son nuestros sistemas constitucionales, la norma superior del sistema irradia a todas las normas inferiores y a las actividades de sus órganos que deben ajustarse a ésta ${ }^{115}$. De esta forma, un sistema coherente será aquel que permita un ejercicio lógico desde la norma superior a la resolución del caso concreto, pasando por las normas procesales y sustantivas aplicables. Por tanto, la legitimidad de las resoluciones en el ámbito interno está dada por la coherencia de la resolución concreta a las obligaciones constitucionales y a las obligaciones internacionales ${ }^{116}$.

El ejercicio interpretativo del que dan cuenta los usos que se han ilustrado en este trabajo, permite que las resoluciones de casos concretos satisfagan estas dos fuentes de coherencia interna, la de origen constitucional y la de origen internacional. Así, por ejemplo, se ofrecen interpretaciones de la norma nacional

113 Artículo $2 \mathrm{CADH}$ : "Si el ejercicio de los derechos y libertades mencionados en el artículo 1 no estuviere ya garantizado por disposiciones legislativas o de otro carácter, los Estados Partes se comprometen a adoptar, con arreglo a sus procedimientos constitucionales y a las disposiciones de esta Convención, las medidas legislativas o de otro carácter que fueren necesarias para hacer efectivos tales derechos y libertades".

114 NúNÉEZ (2015).

115 Hesse (1996).

116 Esta es una característica propia de los sistemas codificados, construidos sobre la idea de sistematicidad y coherencia lógica. Ver: Ruiz Miguel (2002), pp. 270-275. 
que permiten una compatibilidad con la norma internacional, como ocurre en los casos que vimos referidos a la interpretación del alcance del fuero militar, o del derecho al recurso.

\section{CONCLUSIONES}

El contexto de interacción entre el DIDH y el derecho interno en el que nos encontramos, exige un estudio de los mecanismos y criterios que han desarrollado los tribunales internos para solucionar casos concretos. El/la juzgador/a al momento de interpretar y aplicar el derecho ya no se encuentra solo ante la norma nacional, sino que se encuentra frente a una multiplicidad de tratados sobre derechos humanos y jurisprudencia y resoluciones de organismos de protección.

Pese a las dificultades que ha significado la falta de claridad constitucional en torno al rango de los derechos humanos consagrados en tratados internacionales, esto no ha obstado para que la Corte Suprema y las Cortes de Apelaciones hayan avanzado hacia un uso sustantivo del DIDH que se refleja en múltiples manifestaciones de las posibilidades de integración entre el DIDH y el derecho interno. Por una parte, el DIDH ha servido como legitimador de la actividad estatal, planteando criterios para evaluar la corrección de la actuación en conformidad a los estándares internacionales en materia de derechos humanos.

En cuanto a los usos, vimos que el DIDH se ha utilizado para: a) dar concreción a principios; b) interpretar derechos consagrados constitucionalmente para dotarlos de contenido y alcance; c) integrar derechos para configurar uno nuevo o dotar a uno de un nuevo contenido; d) llenar lagunas, y f) fijar pautas para la limitación de derechos.

Esto ha permitido, en definitiva, dar una mejor protección a los derechos, coherencia al ordenamiento jurídico y el cumplimiento de las obligaciones internacionales que ha asumido el Estado de Chile.

Si bien esta senda ha sido progresiva y es una tendencia que va en aumento, no es posible sostener que nos encontremos ante una aplicación generalizada del DIDH, el uso es sostenido y se ha extendido a materias que antes no eran abordadas con una perspectiva de derechos humanos. Sigue pendiente la inclusión de normas internacionales sobre protección de derechos humanos de las mujeres (con la consecuente perspectiva de género), que en general se encuentra ausente en el razonamiento judicial, así como la incorporación de mecanismos propios de razonamiento e interpretación en el DIDH, como son el principio pro persona y los parámetros referidos a la no discriminación. 
Ahondar en el camino referido si bien profundiza uno de los pilares de un Estado democrático de derechos, mejorando la protección de los derechos de la persona, trae consigo desafíos importantes para los/as operadores/as de justicia: conocer, interpretar y aplicar una amplia gama de normas, pero este ejercicio es precisamente lo que Dworkin llamaba "tomarse en serio" los derechos.

\section{Bibliografía CITADA}

Abregú, Martín y Courtis, Christian (1997): La aplicación de los tratados sobre derechos humanos por los tribunales locales (Buenos Aires, CELS- Editores del Puerto).

Aldunate, Eduardo (2010): "La posición de los tratados internacionales en el sistema de fuentes del ordenamiento jurídico chileno a la luz del derecho positivo", en Revista Ius et Praxis (Año 16 № 2), pp. 185-210.

Aguilar, Gonzalo (2009): "La Corte Suprema y la aplicación del Derecho Internacional: un proceso esperanzador", en Revista de Estudios Constitucionales (Año 7 No 1), pp. 91-136.

Aguilar, Gonzalo (2013): “Afinando las cuerdas' de la especial articulación entre el derecho internacional de los derechos humanos y el derecho interno", en Revista de Estudios Constitucionales (Año 11 No 1), pp. 633-654.

Ansuátegui, Francisco (1997): Poder, ordenamiento jurídico y derechos (Madrid, Dykinson).

Aparicio Pérez, Miguel Ángel (1989): "La cláusula interpretativa del artículo 10.2 de la Constitución española como cláusula de integración y apertura constitucional a los derechos fundamentales", en Jueces para la democracia (No 6), pp. 9-18.

Ayala, Carlos (2013): Del diálogo jurisprudencial al control de convencionalidad (México, Editorial Porrúa).

Benadava, Santiago (1992): "Las relaciones entre el derecho internacional y derecho interno ante los tribunales chilenos", en Nuevos enfoques del derecho internacional (Santiago, Editorial Jurídica de Chile).

CanÇADo, Antônio (2001): El Derecho Internacional de los Derechos Humanos en el siglo XXI. (Santiago, Editorial Jurídica de Chile).

CourTis, Christian (2012): Argumentación jurídica y aplicación de los tratados internacionales de los derechos humanos. Guía de estudio de la materia argumentación jurídica y aplicación de los estándares internacionales de los derechos humanos y la perspectiva de género) México: FACSO) [fecha de consulta: 
5.03.2017] [Disponible en http://miguelcarbonell.com/artman/uploads/1/ argumentaci_n_jur_dica.pdf].

Cuenca, Patricia (2012): "La incidencia del Derecho Internacional de los Derechos Humanos en el derecho interno: la interpretación del artículo 10.2 de la Constitución Española”, en Revista de Estudios Jurídicos (No 12), pp. 1-24.

Dulitzky, Ariel (1996): "Los tratados de derechos humanos en el constitucionalismo iberoamericano", en Estudios Especializados de Derechos Humanos, Tomo I (San José, Instituto Interamericano de Derechos Humanos), pp. 129-166.

EzQUiAga, Francisco (2016): Argumentando conforme a los tratados internacionales sobre derechos humanos en las constituciones latinoamericanas. Comunicación presentada en $1^{\text {er }}$ Congreso de Filosofía del Derecho para el mundo latino, Alicante. [Consulta: 5.03.2017]. Disponible: [http://iusfilosofiamundolatino.ua.es/download/EZQUIAGA-Argumentando\%20conforme\%20a\%20 los\%20tratados\%20internacionales\%20_Alicante_.pdf].

FERnÁndeZ, Miguel Ángel (1989): "La reforma al artículo 5º de la Constitución”, en Revista Chilena de Derecho (Vol. 16 No 3), pp. 809-825.

Fernández, Miguel Ángel (2010): "La aplicación por los tribunales chilenos del derecho internacional de los derechos humanos", en: Revista de Estudios Constitucionales (Año 8 No 1), pp. 425-442.

Ferrajoli, Luigi (1995): Derecho y razón (Trotta, Madrid).

Ferrer Mac-Gregor, Eduardo (2012): "Interpretación conforme y control difuso de convencionalidad: el nuevo paradigma para el juez mexicano", en Control de convencionalidad, interpretación conforme y diálogo jurisprudencial (México, Editorial Porrúa), pp. 91-185.

Ferrer Mac-Gregor, Eduardo (2014): "Eficacia de la sentencia interamericana y la cosa juzgada internacional: eficacia de la sentencia interamericana y la cosa juzgada internacional: vinculación directa hacia los pares (res judicata) e indirecta hacia los Estados Parte de la Convención Americana (res interpretata) (sobre el cumplimiento del caso Gelman vs. Uruguay)", en Revista de Estudios Constitucionales (Año 12 No 2), pp. 641-694.

García Barzelato, Ana María (2006): “Tratados Internacionales según la Reforma Constitucional de 2005", en Revista de Derecho Público, (No 68) , pp. 72-84. García SAYÁn, Diego (2005): "Una viva interacción: Corte Interamericana y tribunales internos", en La Corte Interamericana de Derechos Humanos. Un 
cuarto de siglo: 1979-2004 (San José, Corte Interamericana de Derechos Humanos).

GuAstini, Ricardo (2008): Teoría e ideología de la interpretación constitucional (Madrid, Trotta).

HeSSE, Konrad (1996): "El significado de los derechos fundamentales", en Manual de Derecho Constitucional (Madrid, Evap-Marcial Pons).

Henríquez, Miriam (2008): "Jerarquía de los tratados de derechos humanos. Análisis jurisprudencial desde el método de casos", en Revista de Estudios Constitucionales (Año 6 No 2), pp. 73-119.

Henríquez, Miriam (2010): "Análisis jurisprudencial de la aplicación de los tratados de derechos humanos en recursos de protección (1989-2010)", en Revista de Estudios Constitucionales (Año 8 No 2), pp. 745-762.

IrIgOIN, Jeannette (1996): "La Convención Americana sobre Derechos Humanos como derecho interno", en Revista Chilena de Derecho, (Vol. 23 No 1-2), pp. 299-307.

LANDA, César (2010): "La fuerza normativa constitucional de los derechos fundamentales", en Justicia constitucional y derechos fundamentales. Fuerza normativa de la Constitución (Santiago, Konrad Adenauer Stiftung y Centro de Derechos Humanos, Facultad de Derecho Universidad de Chile).

LANDA, César (2012): "Jurisdicción constitucional y jurisdicción internacional: cooperación, conflictos y tensiones", en: Control de convencionalidad, interpretación conforme y diálogo jurisprudencial: una visión desde América Latina y Europa. (México, Editorial Porrúa), pp. 307-332.

Landa, César (s/a): Tribunal Constitucional y Poder Judicial. Una perspectiva desde el Derecho Procesal Constitucional [consulta: 5.03.2017]. Disponible en: [https://www.law.ufl.edu/_pdf/academics/centers/cgr/7th_conference/ Tribunal_Const_y_Poder_Judicial.pdf].

Martín, Lorenzo, Olásolo, Héctor y Ferrer Mac-Gregor, Eduardo (2013): Diálogo jurisprudencial en derechos humanos (Valencia, Tirant lo Blanch).

NASH, Claudio (2010): La concepción de los derechos fundamentales en Latinoamérica (México, Fontamara).

Nash, Claudio (2013): Control de convencionalidad: de la dogmática a la implementación. (México, Editorial Porrúa).

Nash, Claudio (2014): Derechos Humanos y pueblos indígenas en Chile. Análisis jurisprudencial para procesos de consulta en el marco del Convenio 169 de la OIT. (Santiago, Centro de Derechos Humanos Facultad de Derecho Universidad de Chile). 
NASH, Claudio y NúNEzZ, Constanza (2017): “Recepción formal y sustantiva del Derecho Internacional de los Derechos Humanos: experiencias comparadas y el caso chileno", en Boletín Mexicano de Derecho Comparado (No 148), pp. 185-231.

NASH, Claudio y NúNEzZ, Constanza (2015): "La tutela judicial efectiva de los derechos fundamentales en Latinoamérica”, (México, Ubijus e IIDH).

Nogueira, Humberto (2006): "Los tratados internacionales en el ordenamiento público chileno", en Revista chilena de Derecho, (Vol. 23 No 2), pp. 341-380.

Nogueira, Humberto (2007): "Reforma constitucional del 2005 y control de constitucionalidad de tratados internacionales" en Revista de Estudios Constitucionales, (Vol. 5 No 1), pp. 59-88.

Nogueira, Humberto (2012): "El uso del derecho convencional internacional de los derechos humanos en la jurisprudencia del Tribunal Constitucional chileno en el período 2006-2010", en Revista Chilena de Derecho, (Vol. 39 No 1), pp. 149-197.

Nogueira, Humberto (2013): “Diálogo interjurisdiccional y control de convencionalidad entre tribunales nacionales y la Corte Interamericana de Derechos Humanos en Chile", en Anuario de Derecho Constitucional Latinoamericano, (No 19), pp. 511-533.

Núñez Poblete, Manuel (2009): "La función del Derecho Internacional de los Derechos Humanos de la persona en la argumentación de la jurisprudencia constitucional práctica y principios metodológicos" en Revista de Derecho de la Pontificia Universidad Católica de Valparaíso, (Vol. 32 No 1), pp. 487-529.

NúNEz Donald, Constanza (2015): Control de convencionalidad: teoría y aplicación en Chile. Santiago, Editorial Librotecnia.

Pfeffer, Emilio (2003): "Los tratados internacionales sobre derechos humanos y su ubicación en el orden normativo interno", en Revista Ius et Praxis, (Vol. 9 No 1), pp. 467-484.

PeñA, Marisol (2008): "La aplicación del Derecho Internacional de los Derechos Humanos por el Tribunal Constitucional chileno", en Revista de Estudios Constitucionales, (Año 6 No 1), pp. 205-222.

Pérez-Tremps, Pablo (2016): Sistema de justicia constitucional. 2a edición (Madrid, Thomson Reuters-Civitas).

Queralt Jiménez, Argelia (2008): La interpretación de los derechos: del Tribunal de Estrasburgo al Tribunal Constitucional (Madrid, Centro de Estudios Políticos y Constitucionales). 
Risso, Martín (2012): "Interrelación entre el derecho constitucional y el derecho internacional de los derechos humanos", en Anuario Iberoamericano de Justicia Constitucional (No 16), pp. 305-328.

Rey Martínez, Fernando (1989): "El criterio interpretativo de los Derechos Fundamentales conforme a normas internacionales (análisis del artículo 10.2 CE)”, en Revista General de Derecho, (No 537), pp. 3611-3631.

Ruiz Miguel, Alfonso (2002): Una filosofía del derecho en modelos históricos. De la antigüedad a los inicios del constitucionalismo (Madrid, Editorial Trotta).

SAIZ ARNAIZ, Alejandro (1999): La apertura constitucional al derecho internacional y europeo de los derechos humanos. El artículo 10.2 de la Constitución española (Madrid, Consejo General del Poder Judicial).

Sudré, Frédéric (2004): “À propos du 'dialogue des juges' et du controle de conventionalité", en Etudes en l'honneur de Jean-Claude Gautron. Les dynamiques du droit européen en début du siècle (Paris, Ed.. A. Pedone).

TRINIDAD, Pilar (2009): "La aplicación judicial en España de las decisiones de los órganos de base convencional de supervisión de Derechos Humanos creados en el seno de las Naciones Unidas", en La aplicación del Derecho Internacional de los Derechos Humanos en el Derecho español, (Madrid, Universidad Carlos III de Madrid-BOE), pp. 263-280.

VIERA-GALlo, José Antonio y LÜBBERT, Valeria (2012): "Los tratados sobre derechos humanos ante la jurisprudencia chilena”, en Revista de Estudios Internacionales, (No 171), pp. 87-115.

\section{JURISPRUDENCIA CITADA}

Corte Suprema

Rol No 517-2004, de 17 de noviembre de 2004.

Rol No 740-2005, de 25 de abril de 2005.

Rol No 559-2004, de 13 de diciembre de 2006.

Rol No 4325-2006, de 29 de enero de 2007.

Rol No 3125-2004, de 13 de marzo de 2007.

Rol No 3452-2006, de 10 de mayo de 2007.

Rol No 3419-2007, de 13 de noviembre de 2007.

Rol No 1528-2006, de 24 de enero de 2008.

Rol No 6053-2007, de 29 de abril de 2008.

Rol No 2054-2008, de 18 de junio de 2008. 
Rol No 6308-2007, de 8 de septiembre de 2008.

Rol No 5179-2008, de 18 de noviembre de 2008.

Rol No 5132-2008, de 27 de enero de 2009.

Rol No 7351-2009, de 5 de enero de 2010.

Rol No 6-2009, de 15 de marzo de 2010.

Rol No 2787-2010, de 29 de mayo de 2010.

Rol No 4001-2010, de 24 de agosto de 2010.

Rol No 2556-2010, de 16 de septiembre de 2010.

Rol No 258-2011, de 13 de junio de 2011.

Rol No 5411-2010, de 11 de agosto de 2011.

Rol No 7220-2011, de 30 de diciembre de 2011.

Rol No 10090-2011, de 22 de marzo de 2012.

Rol No 5441-2012, de 20 de julio de 2012.

Rol No 7580-2012, de 22 de enero de 2013.

Rol No 9168-2013, de 11 de marzo de 2013.

Rol No 300-2013, de 27 de abril de 2013.

Rol No 920-2013, de 7 de mayo de 2013.

Rol No 2174-2013, de 18 de mayo de 2013.

Rol No 3841-2012, de 19 de junio de 2013.

Rol No 519-2013, de 18 de julio de 2013.

Rol No 3841-2012, de 4 de septiembre de 2013.

Rol No 3784-2013, de 24 de septiembre de 2013.

Rol No 559-2015, de 8 de enero de 2014.

Rol No 10897-2013, de 14 de enero de 2014.

Rol No 16044-2013, de 24 de marzo de 2014.

Rol No 2843-2014, de 8 de abril de 2014.

Rol No 10425-2014, 7 de mayo de 2014.

Rol No 4921-2014, de 9 de junio de 2014.

Rol No 5831-2013, de 10 de junio de 2014.

Rol No 11521-2014, de 12 de junio de 2014.

Rol No 21499-2014, de 8 de octubre de 2014.

Rol No 25491-2014, de 27 de noviembre de 2014.

Rol No 1059-2015, de 20 de enero de 2015.

Rol No 29359-2014, de 29 de enero de 2015. 
Rol No 3402-2015, de 9 de marzo de 2015.

Rol No 19354-2014, de 9 de abril de 2015.

Rol No 22356-2014, de 20 de abril de 2015.

Rol No 3581-2015, de 7 de mayo de 2015.

Rol No 1187-2014, de 28 de mayo de 2015.

Rol No 1579-2015, de 8 de julio de 2015.

Rol No 23808-2014, de 5 de agosto de 2015.

Rol No 92795-2016, de 1 de diciembre de 2016.

Rol No 46451-2016, de 19 de diciembre de 2016.

Rol No 87743-2016, de 2 de febrero de 2017.

\section{Cortes de Apelaciones}

Corte de Apelaciones de La Serena. Rol No 152-2005, 1 de junio de 2005.

Corte de Apelaciones de Valdivia. Rol No 20-2007,10 de julio de 2007.

Corte de Apelaciones de Santiago. Rol No 4344-2006, 19 de julio de 2007.

Corte de Apelaciones de Concepción. Rol No 3620-2004, 27 de marzo de 2008.

Corte de Apelaciones de Santiago. Rol No 1701-2007, 31 de marzo de 2008.

Corte de Apelaciones de Santiago. Rol No 6885-2007, 31 de octubre de 2009.

Corte de Apelaciones de Temuco. Rol No 1705-2009, 21 de enero de 2010.

Corte de Apelaciones de Rancagua. Rol No 23-2010, 16 de marzo de 2010.

Corte de Apelaciones de Santiago. Rol No 728-2010, 14 de mayo de 2010.

Corte de Apelaciones de Santiago. Rol No 3383-2009, 8 de junio de 2010.

Corte de Apelaciones de San Miguel. Rol No 193-2010, 14 de junio de 2010.

Corte de Apelaciones de Santiago. Rol No 2444-2009, 15 de junio de 2010.

Corte de Apelaciones de Santiago. Rol No 3427-2009, 16 de junio de 2010.

Corte de Apelaciones de Talca. Rol No 986-07, 3 de noviembre de 2010.

Corte de Apelaciones de La Serena. Rol No 262-2010, 27 de noviembre de 2010.

Corte de Apelaciones de Temuco. Rol No 342-2011, 16 de diciembre de 2011.

Corte de Apelaciones de Temuco. Rol No 1136-2011, 21 de diciembre de 2011.

Corte de Apelaciones de Punta Arenas. Rol No 116-2011, 20 de enero de 2012.

Corte de Apelaciones de Santiago. Rol No 808-2012, 12 de abril de 2012.

Corte de Apelaciones de Temuco. Rol No 454-2012, 3 de junio de 2012.

Corte de Apelaciones de Santiago. Rol No 10140-2012, 28 de junio de 2012.

Corte de Apelaciones de Temuco. Rol No 449-2012, 5 de agosto de 2012. 
Corte de Apelaciones de Temuco. Rol No 604-2012, 3 de septiembre de 2012. Corte de Apelaciones de Temuco. Rol No 545-2010, 15 de diciembre de 2012. Corte de Apelaciones de San Miguel. Rol No 1745-2012, 18 de diciembre de 2012. Corte de Apelaciones de Santiago. Rol No 19-2013, 21 de enero de 2013. Corte de Apelaciones de Temuco. Rol No 46-2013, 27 de febrero de 2013. Corte de Apelaciones de Valdivia. Rol No 8-2013, 13 de marzo de 2013. Corte de Apelaciones de Santiago. Rol No 1826-2012, 22 de marzo de 2013. Corte de Apelaciones de Temuco. Rol No 378-2013, 11 de abril de 2013. Corte de Apelaciones de Santiago. Rol No 113-2013, 24 de abril de 2013. Corte de Apelaciones de Santiago. Rol No 671-2013, 7 de mayo de 2013. Corte de Apelaciones de Temuco. Rol No 378-2013, 11 de mayo de 2013. Corte de Apelaciones de Santiago. Rol No 8413-2013, 1 de agosto de 2013. Corte de Apelaciones de San Miguel. Rol No 1537-2013, 18 de noviembre de 2013. Corte de Apelaciones de Antofagasta. Rol No 68-2013, 7 de diciembre de 2013. Corte de Apelaciones de Valparaíso. Rol No 1526-2013, 10 de diciembre de 2013. Corte de Apelaciones de Concepción. Rol No 671-2012, 21 de diciembre de 2013. Corte de Apelaciones de Temuco. Rol No 982-2013, 31 de enero de 2014. Corte de Apelaciones de Concepción. Rol No 26-2014, 2 de marzo de 2014. Corte de Apelaciones de San Miguel. Rol No 32-2014, 3 de marzo de 2014. Corte de Apelaciones de Concepción. Rol No 26-2014, 21 de marzo de 2014. Corte de Apelaciones de Temuco. Rol No 253-2014, 24 de mayo de 2014. Corte de Apelaciones de Temuco. Rol No 8828-2013, 21 de julio de 2014. Corte de Apelaciones de Santiago. Rol No 38520-2014, 5 de septiembre de 2014. Corte de Apelaciones de Santiago. Rol No 36243-2014, 7 de octubre de 2014. Corte de Apelaciones de Temuco. Rol No 888-2014, 21 de octubre de 2014. Corte de Apelaciones de Santiago. Rol No 66458-2014, 18 de noviembre de 2014. Corte de Apelaciones de Iquique. Rol No 496-2014, 26 de noviembre de 2014. Corte de Apelaciones de Temuco. Rol No 86-2015, 20 de febrero de 2015. Corte de Apelaciones de Iquique. Rol No 56-2015, 31 de marzo de 2015. Corte de Apelaciones de Santiago. Rol No 427-2015, 10 de abril de 2015. Corte de Apelaciones de Concepción. Rol No 78-2015, 4 de mayo de 2015. Corte de Apelaciones de Concepción. Rol No 97-2015, 8 de junio de 2015. Corte de Apelaciones de San Miguel. Rol No 334/2015, 9 de julio de 2015. Corte de Apelaciones de San Miguel. Rol No 1106-2015, 11 de diciembre de 2015. 
Corte de Apelaciones de Santiago. Rol No 12571-2015, 27 de enero de 2016. Corte de Apelaciones de Santiago. Rol No 100344-2015, 7 de marzo de 2016. Corte de Apelaciones de Santiago. Rol No 13001-2015, 29 de marzo de 2016. Corte de Apelaciones de San Miguel. Rol No 2052-2015, 14 de abril de 2016. Corte de Apelaciones de Arica. Rol No 189-2016, 5 de agosto de 2016.

Corte de Apelaciones de Temuco. Rol No 6345-2016, 21 de diciembre de 2016.

\section{Tribunal Constitucional de Chile}

Rol No 198-1995, de 4 de enero de 1995.

Rol No 346-2002, de 8 de mayo de 2002.

Rol No 1288-2009, de 9 de agosto de 2009.

Roles Nos. 2387 y 2388 acumulados.

Rol No 2026-2011, de 14 de agosto de 2012. 